\title{
Biodiversidad y endemismo de los caracoles terrestres Megalobulimus y Systrophia en la Amazonia occidental
}

\author{
Biodiversity and endemism of the western Amazonia land snails Megalobulimus \\ and Systrophia
}

\author{
Rina Ramírez ${ }^{1,2}$, Víctor Borda ${ }^{1,2}$, Pedro Romero ${ }^{1,2}$, Jorge Ramirez ${ }^{1,2}$, Carlos Congrains ${ }^{1,2}$, \\ Jenny Chirinos ${ }^{1,2}$, Pablo Ramírez ${ }^{3}$, Luz Elena Velásquez ${ }^{4}$, Kember Mejía ${ }^{5}$
}

1 Museo de Historia Natural, Universidad Nacional Mayor de San Marcos. Apartado 14-0434, Lima14, Perú.

2 Laboratorio de Sistemática Molecular y Filogeografía, Facultad de Ciencias Biológicas, Universidad Nacional Mayor de San Marcos, Av. Venezuela s/n, Lima-1, Perú.

3 Laboratorio de Microbiología Molecular y Biotecnología, Facultad de Ciencias Biológicas, Universidad Nacional Mayor de San Marcos.

4 Programa de Estudio y Control de Enfermedades Tropicales/PECET, Universidad de Antioquia, Coll $52-59$, - 52 - 59, Sede de investigación Universitaria (SIU), Laboratorio 730, Medellín, Colombia.

5 IIAP: Instituto de Investigaciones de la Amazonia Peruana, Apartado

784, Iquitos, Perú.

E-mail Rina Ramírez:

rinarm@yahoo.com

Presentado: 20/11/2011

Aceptado: 16/07/2012

Publicado online: 01/10/2012

\begin{abstract}
Resumen
En este trabajo realizamos un estudio biogeográfico de dos géneros de caracoles terrestres amazónicos, Megalobulimus (Strophocheilidae) y Systrophia (Scolodontidae). Se utilizaron individuos colectados en diversas localidades de la Amazonia peruana así como información bibliográfica. Se utilizaron los marcadores moleculares 5.8S-ITS2-28S rRNA y 16S rRNA para reconstruir filogenias y obtener hipótesis sobre las relaciones evolutivas entre los géneros amazónicos y otras especies de distribución global. La filogenia nuclear permitió determinar la posición evolutiva de ambos géneros y la filogenia mitocondrial permitió la diferenciación de las especies a nivel intragenérico. Megalobulimus formó parte del clado no-achatinoideo en la filogenia de los gastrópodos Stylommatophora, como lo esperado, pero no pudo ser demostrada su cercanía a la familia Acavidae, mientras que Systrophia quedó fuera de los dos clados establecidos, formando uno basal dentro de los Stylommatophora. El gen mitocondrial 16S rRNA permitió diferenciar a las especies de Megalobulimus, actuando como código de barras de ADN de estos caracoles comestibles. El análisis de distribución geográfica reveló varios endemismos para la Amazonia peruana para especies de ambos géneros, resaltando las unidades biogeográficas de Chanchamayo e Inambari.
\end{abstract}

Palabras claves. 16S rRNA, ITS, sistemática molecular, código de barras de ADN, endemismos

\section{Abstract}

In this work we performed a biogeographic study of two genera of Amazonian land snails, Megalobulimus (Strophocheilidae) and Systrophia (Scolodontidae). We used samples from different regions of the Peruvian Amazon, as well as bibliographic information. We analyzed both nuclear (5.8S-ITS2-28S rRNA) and mitochondrial (16S rRNA) genes to reconstruct phylogenies and obtain hypotheses concerning the evolutionary relationships among Amazonian genera and other species with global distribution. The nuclear phylogeny allowed us to determine the evolutionary position of both genera, and the mitochondrial phylogeny permitted the differentiation of species at the intrageneric level. We found that Megalobulimus clustered with the non-achatinoid clade within Stylommatophora, as expected, but its relationship to family Acavidae could not be demonstrated. Systrophia did not cluster with any of the two established clades, but formed a basal one within Stylommatophora. The mitochondrial gene 16S rRNA allowed us to differentiate Megalobulimus species, and performed well for DNA barcoding of these edible snails. Biogeographical analysis revealed several endemic species in the Peruvian Amazon within both genera, highlighting the Chanchamayo and Inambari biogeographic units.

Keywords. 16S rRNA, ITS, molecular systematics, DNA barcode, endemism

\section{Introducción}

América del Sur alberga la mayor biodiversidad del mundo, aunque aún no se conocen todas sus especies que la componen, en especial las de la Amazonia (Vieira et al. 2008). En este continente existen grandes áreas de endemismos como la cuenca amazónica occidental, las vertientes boscosas de los Andes y el bosque atlántico de Brasil (Moritz et al. 2000), que están experimentando una acelerada pérdida de hábitats, por lo que son conocidas también como "hotspots" (Myers 1988; Myers et al. 2000). Los moluscos son uno de los componentes conspicuos de esa biodiversidad, el segundo phylum con mayor número de especies animales (Ponder \& Lindberg 2008), pero al mismo tiempo con muy pocos estudios en la Amazonia (Bruggen 1995). Entre los más estudiados estan los géneros Megalobulimus (Fam. Strophocheilidae) y Systrophia (Fam. Scolodontidae); el primero alberga caracoles comestibles y la especie de mayor tamaño en América, M. popelairianus (163 mm) (Bequaert 1948), y Systrophia tiene conchas aplanadas de no más de 25.5 mm (Ramírez 1993). Ambas familias son endémicas de América del Sur (Parodiz 1982) y los géneros mencionados están bien representados en la Amazonia occidental. Los Megalobulimus (Fig. 1) son conocidos en el Perú como "congompes" (Douro- jeanni 1965; Ramírez \& Cáceres 1991; Borda et al. 2010), son utilizados como alimento en Perú (Castro et al. 1976; Ramírez \& Cáceres 1991) y Ecuador (Bequaert 1948). Los Systrophia constituyen los moluscos más representativos de los bosques de la Amazonia occidental; y especies como $S$. helicycloides (Fig. 2) han permitido desarrollar estudios filogeográficos que han demostrando los efectos históricos de la dinámica de la Amazonia (Romero 2010).

El interés creciente por las propiedades regeneradoras o rejuvenecedoras de la piel atribuidas a los caracoles terrestres (Abad 1996; Wang et al. 2010) ha propiciado extracciones indiscriminadas para su comercialización informal. Poco es lo que se ha logrado en el cultivo de especies nativas (Campoverde 1992; Rengifo et al. 2004), a diferencia de lo que sucede con el introducido caracol europeo Helix aspersa que se ha convertido en plaga de cultivos principalmente de la costa de Perú.

En la actualidad se sabe que no sólo la diversidad de especies, sino que la diversidad genética juega un papel muy importante en la biodiversidad (Primack \& Rodríguez 2001). Estudios en genómica están resolviendo una serie de incógnitas que permiten un mejor aprovechamiento de la biodiversidad al emplear se- 
cuencias de ADN como "código de barras" (Hebert et al. 2003a, b); en torno a esta idea central se ha formado un consorcio a nivel mundial (CBOL) que promueve "un estándar global para identificar especimenes biológicos". Con esta iniciativa, las especies quedarán mejor referenciadas, añadiendo nuevas oportunidades económicas con especies promisorias para el biocomercio como las correspondientes al género Megalobulimus. El estudio de marcadores específicos en el genoma mitocondrial de caracoles terrestres nativos puede proveernos de un sello de garantía para nuestras especies y sus poblaciones con lo que no sólo podamos salvaguardar nuestros recursos sino también explotarlos adecuadamente (Tundisi \& Matsumura-Tundisi 2008).

En este trabajo haremos un análisis biogeográfico, con especial referencia a la Amazonia occidental, de dos grupos endémicos
A

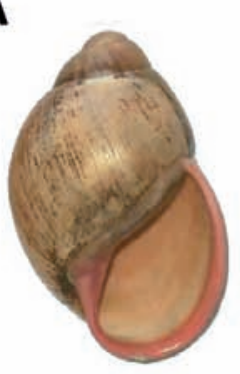

B

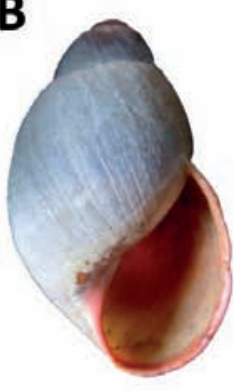

C

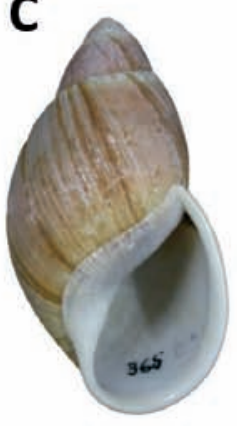

$\mathbf{F}$

$\mathbf{E}$
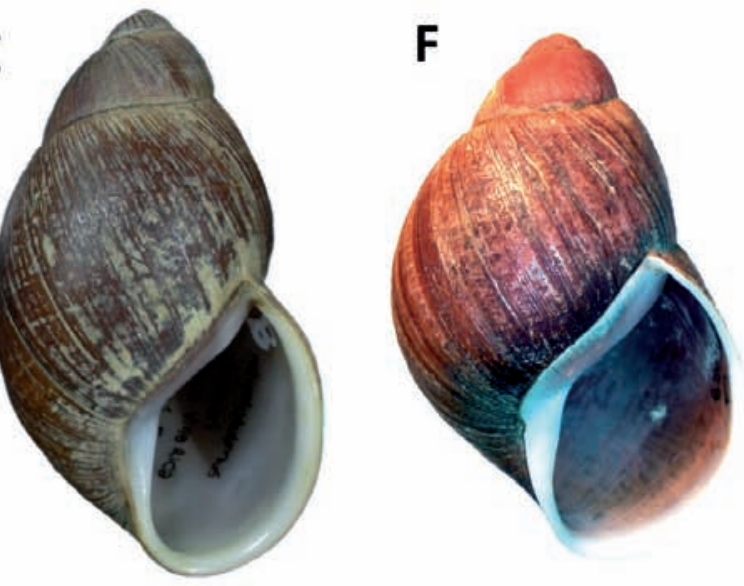

H

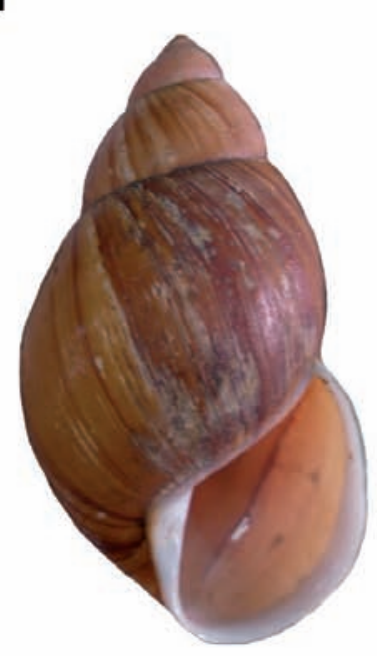

I

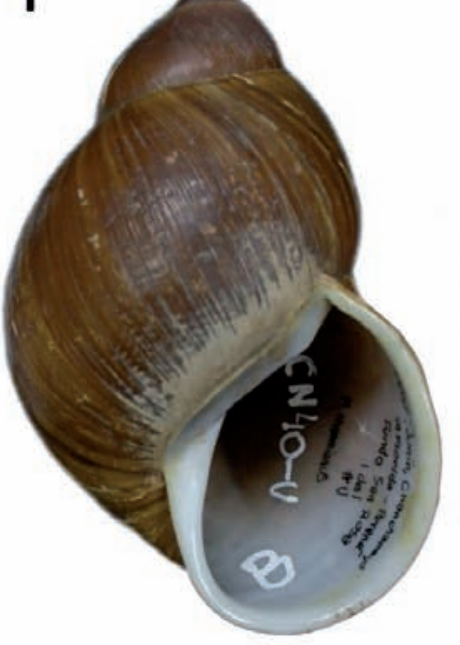

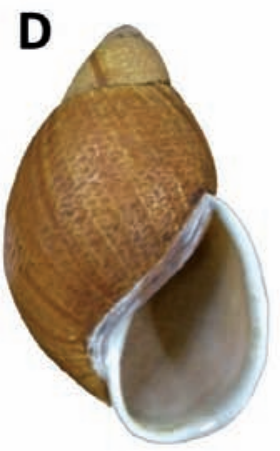

G

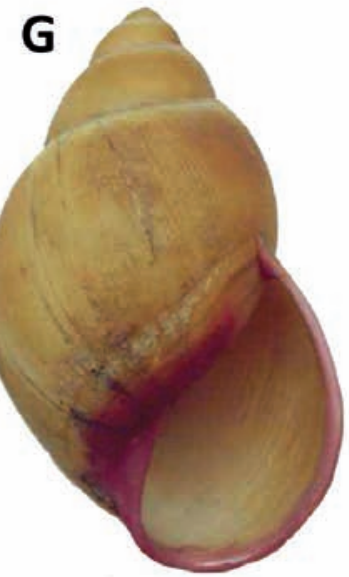

$20 \mathrm{~mm}$

Figura 1. Conchas de Megalobulimus spp. procedentes de Perú (A-F, H-J) y Colombia (G.). (A) M. capillaceus (Dpto. San Martín). (B) M. separabilis (Dpto. Huánuco). (C) M. leucostoma (Dpto. Cusco). (D) M. carrikeri (Dpto. Junín). (E) M. huascari (Dpto. Junín). (F) M. lichtensteini (Dpto. Amazonas). (G) M. oblongus (Dpto. Caldas, Colombia). (H) M. maximus (Dpto. Madre de Dios). (I) M. thammianus (Dpto. Junín). (J) M. popelairianus (Dpto. Madre de Dios). 


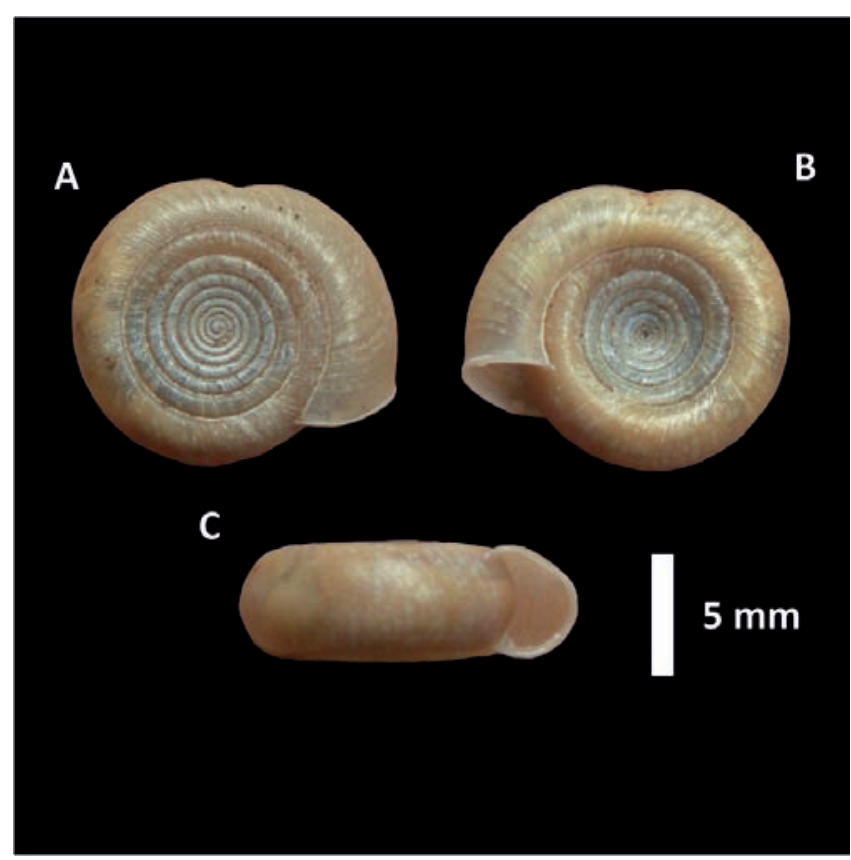

Figura 2. Concha de Systrophia helicycloides, familia Scolodontidae (Perú, Dpto. Madre de Dios). Vista: (A) apical, (B) umbilical y (C) Vista apertural. de América del Sur, los caracoles terrestres de los géneros $\mathrm{Me}$ galobulimus (Strophocheilidae) y Systrophia (Scolodontidae), enfatizando el análisis molecular, así como un comentario sobre el uso de "congompes".

\section{Material y métodos}

Material biológico.- El material usado para el análisis molecular de Megalobulimus spp. (Fig. 1) fue colectado en varias localidades de la Amazonia peruana, así como en mercados de abastos de Tarapoto y Juanjui (Dpto. San Martín) e Iquitos (Dpto. Loreto: Mercado Belén), y el de Systrophia helicycloides (Fig. 2) en el Dpto. Madre de Dios (Tab. 1). Los especimenes fueron conservados en etanol 96\% y depositados en el Departamento de Malacología y Carcinología del Museo de Historia Natural de la Universidad Nacional Mayor de San Marcos.

Extracción, amplificación y secuenciamiento de ADN.El ADN total fue aislado de músculo del pie de caracoles preservados en etanol usando una modificación del método de CTAB (Doyle \& Doyle 1987; Ramírez 2004). Un segmento variable del gen mitocondrial $16 \mathrm{~S}$ rRNA fue amplificado por PCR usando primers y protocolos descritos por Ramírez (2004). Para el marcador nuclear se usaron los primers LSU1 y LSU3 de Wade y Morgan (2000), para amplificar la región 3' del gen 5.8S rRNA (aprox. 80pb), el ITS-2 completo y la región 5' del gen $28 \mathrm{~S}$ rRNA (aprox. $370 \mathrm{pb}$ ). Ambas hebras fueron secuen-

Tabla 1. Procedencia de los especímenes de Megalobulimus y Systrophia de los que se obtuvieron secuencias en este estudio, con sus números de accesión en el GenBank (Benson et al. 2011).

\begin{tabular}{|c|c|c|c|c|c|c|}
\hline & Especie & Individuo & Procedencia & Coordenadas (LS/LO) & Nuclear & 16S rRNA \\
\hline 1 & M. capillaceus & Moy-M16-6 & SM. Moyobamba & $6^{\circ} 02^{\prime} 11.2^{\prime \prime} / 76^{\circ} 58^{\prime} 26.2^{\prime \prime}$ & & JN604725 \\
\hline 2 & M. capillaceus & Sap-M61-10.2 & SM. Saposoa & $6^{\circ} 56^{\prime} / 76^{\circ} 47^{\prime}$ & JN604718 & JN604726 \\
\hline 3 & M. capillaceus & Tar-M19-1 & SM. Tarapoto & $6^{\circ} 28^{\prime} 18^{\prime \prime} / 76^{\circ} 22^{\prime} 14.6^{\prime \prime}$ & JN604719 & JN604727 \\
\hline 4 & M. huascari & JSP-N47-1 & JU. San Chirio del Palomar & $10^{\circ} 48^{\prime} 43.8^{\prime \prime} / 75^{\circ} 12^{\prime} 02.8^{\prime \prime}$ & & JN604728 \\
\hline 5 & M. huascari & JLE-N46-2 & JU. Mina La Esperanza & $11^{\circ} 14^{\prime} 27.5^{\prime \prime} / 75^{\circ} 22^{\prime} 02.6^{\prime \prime}$ & & JN604729 \\
\hline 6 & M. huascari & Utc-N55-1 & JU: Uctuyacu & $11^{\circ} 17^{\prime} 19.5^{\prime} / 7^{\circ} 19^{\prime} 29.4^{\prime \prime}$ & & JN604730 \\
\hline 7 & M. lichtensteini & Shu-M73-17.2 & CA:Shumba & $5^{\circ} 32^{\prime} 33.07^{\prime \prime} / 78^{\circ} 48^{\prime} 59.15^{\prime \prime}$ & & JN604731 \\
\hline 8 & M. lichtensteini & Nar-N29-2 & AM. Naranjito & $5^{\circ} 49^{\prime \prime} / 78^{\circ} 16^{\prime \prime}$ & & JN604732 \\
\hline 9 & M. lichtensteini & Nar-M88-1 & AM. Naranjito & $5^{\circ} 49^{\prime \prime} / 78^{\circ} 16^{\prime \prime}$ & & JN604733 \\
\hline 10 & M. maximus & Ink-M86-1 & MD. Inkaterra & $12^{\circ} 35^{\prime} / 69^{\circ} 05^{\prime}$ & JN604720 & JN604734 \\
\hline 11 & M. maximus & Ink-M100-2 & MD. Inkaterra & $12^{\circ} 35^{\prime} / 69^{\circ} 05^{\prime}$ & JN604721 & JN604735 \\
\hline 12 & M. maximus & Biot-N70-2 & MD. Cuzco Amazónico-Biotrop (Inkaterra) & $12^{\circ} 35^{\prime} / 69^{\circ} 05^{\prime}$ & & JN604736 \\
\hline 13 & M. popelairianus & TarM-M90-13 & SM. Tarapoto: Mercado & & & JN604737 \\
\hline 14 & M. popelairianus & TarM-N58-1 & SM. Tarapoto: Mercado & & & JN604738 \\
\hline 15 & M. popelairianus & SapJM-M78-1 & SM. Juanjui: Mercado & & & JN604739 \\
\hline 16 & M. popelairianus & MIq-H14-3 & LO. Iquitos: Mercado & & & JN604740 \\
\hline 17 & M. popelairianus & Ink-M85-2 & MD. Inkaterra & $12^{\circ} 35^{\prime} / 69^{\circ} 05^{\prime}$ & & JN604741 \\
\hline 18 & M. popelairianus & Rio-M67-9.1 & SM. Rioja & $6^{\circ} 4^{\prime} 9^{\prime \prime} / 77^{\circ} 10^{\prime} 83^{\prime \prime}$ & JN604722 & JN604742 \\
\hline 19 & M. popelairianus & SapCH-M95-10.4 & SM. Saposoa-Chambira & ca. $6^{\circ} 56^{\prime} / 76^{\circ} 47^{\prime}$ & & JN604743 \\
\hline 20 & M. separabilis & HuA-N36 & HU. Ambo & $10^{\circ} 07^{\prime} 43^{\prime \prime} /$ / 76²'48.1" & & JN604744 \\
\hline 21 & M. thammianus & DBo-N39-u & JU. Don Bosco [Chanchamayo] & 11¹0'38.7" / 75²1'18.3" & & JN604745 \\
\hline 22 & M. thammianus & Flo-N40-u & JU. La Florida (Sr. Zúñiga) [Chanchamayo] & $10^{\circ} 49^{\prime} 54.9^{\prime \prime} / 75^{\circ} 06^{\prime} 40.9^{\prime \prime}$ & & JN604746 \\
\hline 23 & M. thammianus & Flo-N42-1 & JU. La Florida (Sra Huamaní) [Chanchamayo] & $10^{\circ} 50^{\prime} 19.0^{\prime \prime} / 75^{\circ} 06^{\prime} 00.8^{\prime \prime}$ & & JN604747 \\
\hline 24 & M. thammianus & Oco-H25-1 & JU. Puerto Ocopa & $11^{\circ} 05^{\prime} 39.2^{\prime \prime} / 74^{\circ} 18^{\prime} 31.3^{\prime \prime}$ & & JN604748 \\
\hline 25 & M. thammianus & Biot-N27-8a & MD. Cuzco Amazónico (Inkaterra)-Biotrop & $12^{\circ} 35^{\prime} / 69^{\circ} 05^{\prime}$ & & JN604749 \\
\hline 26 & S. helicycloides & Ami-CLo-P20-a & MD. Los Amigos & $12^{\circ} 34.15^{\prime} / 70^{\circ} 6.06^{\prime}$ & JN604723 & \\
\hline 27 & S. helicycloides & Ink-Pal-P29-g & MD. Inkaterra & $12^{\circ} 35^{\prime} / 69^{\circ} 05^{\prime}$ & JN604724 & \\
\hline
\end{tabular}

Perú, dptos. Amazonas (AM), Cajamarca (CA), Huánuco (HU), Junín (JU), Loreto (LO), Madre de Dios (MD) y San Martín (SM). 
Tabla 2.Taxa usados en las filogenias moleculares basadas en el marcador nuclear $>5.8 S$ rRNA-ITS2-28S rRNA $<$ y el marcador mitocondrial 16S rRNA. Las 72 secuencias se encuentran en el GenBank y proceden de Wade et al. (2006), Herbert y Mitchell (2009) (1), Ramírez et al. (2011) (2), Rowson et al. (2011) (3), Moussalli et al. (2009) (4), Breure et al. (2010) (5) y del presente estudio (6).

\begin{tabular}{|c|c|c|c|}
\hline \multirow{2}{*}{\multicolumn{2}{|c|}{$\begin{array}{l}\text { Familia } \\
\text { Especie } \\
\text { Phylum Mollusca, Clase Gastropoda, Subclase Pulmonata, Orden Eupolmonata, Suborden Stylommatophora } \\
\text { Infraorden Orthurethra }\end{array}$}} & \multicolumn{2}{|c|}{ Número de Accesión } \\
\hline & & Nuclear & 16S rRNA \\
\hline \multirow[t]{2}{*}{ Vertiginidae } & Vertigo antivergo (Draparnaud 1801) & AY014027 & \\
\hline & Gastrocopta armifera (Say 1821) & AY841286 & \\
\hline Enidae & Mastus pupa (Bruguière 1792) & AY014038-9 & \\
\hline Partulidae & Partula suturalis Pfeiffer 1855 & AY014042 & \\
\hline \multicolumn{4}{|c|}{ Infraorden Mesurethra } \\
\hline \multirow[t]{5}{*}{ Clausiliidae } & Clausilia bidentata (Ström 1765) & AY014051 & \\
\hline & Macrogastra rolphii (Turton 1826) & AY014052 & \\
\hline & Cochlodina laminata (Montagu 1803) & AY014047 & \\
\hline & Albinaria xantostoma (Boettger 1883) & AY014048 & \\
\hline & Pinguiphaedusa platydera (Martens 1876) & AY841292 & \\
\hline \multicolumn{4}{|c|}{ Infraorden Elasmognatha } \\
\hline Succineidae & Succinea striata (Krauss 1848) & AY841295 & \\
\hline Athoracophoridae & Athoracophorus bitentaculatus (Quoy y Gaimard 1832) & AY014018 & \\
\hline \multicolumn{4}{|c|}{ Infraorden Sigmurethra } \\
\hline \multirow[t]{4}{*}{ Orthalicidae } & Bulimulus sporadicus (d'Orbigny 1835) & AY841299 & \\
\hline & Orthalicus ponderosus Strebel y Pfeffer $1882^{(5)}$ & HM027506 & \\
\hline & Placostylus eddystonensis (Pfeiffer 1855) & AY841296-7 & \\
\hline & Bostryx aguilari Weyrauch $1967^{(2,6)}$ & $\begin{array}{l}\text { HM116230, } \\
\text { IN604717 }\end{array}$ & \\
\hline Amphibulimulidae & Gaeotis nigrolineata Shuttleworth 1854 & AY841301 & \\
\hline Cerionidae & Cerion incanum (Binney 1851) & AY014060 & \\
\hline Ferussaciidae & Ferussacia foilliculus (Gmelin 1791) & AY841302 & \\
\hline \multirow[t]{3}{*}{ Subulinidae } & Subulina striatella (Rang 1831) & AY014061 & \\
\hline & Rumina decollata (Linnaeus 1758) & AY014065 & \\
\hline & Bocageia sp. & AY014062 & \\
\hline Achatinidae & Limicolaria kambeul (Bruguière 1792) & AY014072 & \\
\hline Spiraxidae & Euglandina rosea (Férussac 1821) & AY014074 & \\
\hline Tesatacellidae & Testacella scutulum Sowerby 1821 & AY014075 & \\
\hline \multirow[t]{5}{*}{ Streptaxidae } & Gonaxis quadrilateralis Preston 1910 & AY014076 & \\
\hline & Gonospira sp. & AY014077 & \\
\hline & Augustula braueri (Martens 1898) (3) & & HQ328370 \\
\hline & Edentulina minor (Morelet 1851) ${ }^{(3)}$ & & HQ328283 \\
\hline & Streptostele kilimanjaroensis Blume $1965^{(3)}$ & & HQ328274 \\
\hline \multirow[t]{8}{*}{ Strophocheilidae } & Megalobulimus capillaceus (Pfeiffer 1855) (6) & JN604718-9 & JN604725-7 \\
\hline & M. huascari (Tschudi 1852) ${ }^{(6)}$ & & JN604728-30 \\
\hline & M. lichtensteini (Albers 1854) ${ }^{(6)}$ & & JN604731-3 \\
\hline & Megalobulimus maximus (Sowerby 1825) ${ }^{(6)}$ & JN604720-1 & JN604734-6 \\
\hline & Megalobulimus oblongus (Müller 1774) & AY014078 & \\
\hline & Megalobulimus popelairianus (Nyst 1845) ${ }^{(6)}$ & JN604722 & JN604737-43 \\
\hline & M. separabilis (Fulton 1903) & & JN604744 \\
\hline & M. thammianus (Martens 1876) ${ }^{(6)}$ & & JN604745-9 \\
\hline \multirow[t]{2}{*}{ Dorcasidae } & Dorcasia alexandri Gray 1938 & AY014079 & \\
\hline & Trigonephrus globulus (Müller 1774) & AY014080-1 & \\
\hline \multirow[t]{2}{*}{ Acavidae } & Acavus phoenix (Pfeiffer 1854) & AY014082-3 & \\
\hline & Leucotaenius proctori (Sowerby 1894) & AY014084-5 & \\
\hline Caryodidae & Caryodes dufresnii Leach 1815 & AY014086 & \\
\hline \multirow[t]{5}{*}{ Rhytididae } & Rhytida stephenesis Powell 1930 & AY014087 & \\
\hline & Schizoglossa sp. & AY014088 & \\
\hline & Natalina knysnaensis (Pfeiffer1 1846) ${ }^{(4)}$ & & FJ262219 \\
\hline & Natalina kraussi (Pfeiffer 1846) ${ }^{(4)}$ & & FJ262230 \\
\hline & Natalina schaerfiae (Pfeiffer 1861) ${ }^{(4)}$ & & FJ262237 \\
\hline Chlamydephoridae & Chlamydephorus burnupi & AY014089 & \\
\hline Haplotrematidae & Haplotrema vancouverense (Lea 1839) & AY014090 & \\
\hline Corillidae & Corilla adamsi Gude 1914 & AY014091-2 & \\
\hline Punctidae & Laoma sp. & AY014093 & \\
\hline Charopidae & Suteria ide (Gray 1850) & AY014094-5 & \\
\hline
\end{tabular}


Tabla 2. Continuación.

\begin{tabular}{|c|c|c|}
\hline Familia & Especie & Número de Accesión \\
\hline Otoconchidae & Otoconcha dimidiata (Pfeiffer 1853) & AY014096 \\
\hline \multirow[t]{2}{*}{ Discidae } & Discus rotundatus (Müller 1774) & AY014097 \\
\hline & Anguispira alternata (Say 1816) & AY841309 \\
\hline Euconulidae & Euconulus fulvus (Müller 1774) & AY014098 \\
\hline Helicarionidae & Plegma caelatura (Férussac 1821) & AY014103 \\
\hline Ariophantidae & Ratnadvipia sp. & AY841312 \\
\hline Urocyclidae & Elisolimax flavescens (Keferstein 1866) ${ }^{(1)}$ & EU622017 \\
\hline Pristilomatidae & Vitrea crystallina (Müller 1774) & AY014113 \\
\hline Oxychilidae & Oxychilus alliarius (Miller 1822) & AY014114 \\
\hline Milacidae & Tandonia budapestensis (Hazay 1881) [= Milax budapestensis] & AY014117 \\
\hline Poligyridae & Triodopsis alleni (Wetherby 1883) & AY841316 \\
\hline \multirow[t]{2}{*}{ Helicidae } & Cantareus aspersus (Müller 1774) [= Helix aspersa $]$ & AY014128 \\
\hline & Helix pomatia Linnaeus 1758 & AY841333 \\
\hline Bradybaenidae & Bradybaena similaris (Férussac 1821) & AY014138 \\
\hline \multirow[t]{2}{*}{ Helminthoglyptidae } & Cepolis streatori (Pilsbry 1889) & AY841346 \\
\hline & Monadenia fidelis (Gray 1834) & AY014142 \\
\hline Arionidae & Arion hortensis Férussac 1819 & AY014143 \\
\hline Philomycidae & Philomycus carolinianus (Bosc 1802) & AY841349 \\
\hline \multirow[t]{5}{*}{ Scolodontidae } & Systrophia eatoni Baker $1913^{(2)}$ & $\begin{array}{l}\text { HM067823, } \\
\text { HM116229 }\end{array}$ \\
\hline & S. (Entodina) jekylli (Baker 1913) ${ }^{(2)}$ & HM067824 \\
\hline & Scolodonta sp.1 ${ }^{(2)}$ & HM067825 \\
\hline & Scolodonta sp.2 ${ }^{(2)}$ & HM116227-8 \\
\hline & S. helicycloides ${ }^{(6)}$ & JN604723-4 \\
\hline \multicolumn{3}{|c|}{ Pulmonados no-Stylommatophora } \\
\hline & \multicolumn{2}{|l|}{ Orden Eupulmonata } \\
\hline Ellobiidae & Laemodonta sp. & AY014147 \\
\hline \multicolumn{3}{|c|}{ Orden Basommatophora } \\
\hline Siphonariidae & Siphonaria pectinata (L. 1758) & AY014149-50 \\
\hline \multicolumn{3}{|c|}{ Orden Systellomatophora } \\
\hline Veronicellidae & Laevicaulis alte (Férussac 1823) & AY014151 \\
\hline \multicolumn{3}{|c|}{ Phylum Mollusca, Clase Gastropoda, Subclase Opisthobranchia, Orden Anaspidea } \\
\hline Aplysiidae & Aplysia punctata Cuvier 1803 & AY014153-4 \\
\hline
\end{tabular}

ciadas usando los servicios de Macrogen Inc (USA y Korea). La edición manual de las secuencias fue realizada usando Chromas (McCarthy 1996); el ensamblaje de las secuencias consenso fue llevado a cabo mediante Cap3win (Huang \& Madan 1999). Las secuencias fueron depositadas en el GenBank (JN604717JN604749) (Tablas 1 y 2).

Marcador nuclear.- Fueron obtenidas siete secuencias del marcador nuclear $>5.8 \mathrm{~S}$ rRNA-ITS2-28S $r R N A<$, cinco correspondiendo a tres especies de Megalobulimus y dos a Systrophia helicycloides (Tabla 1). Su inclusión en la filogenia nuclear de los pulmonados Stylommatophora fue evaluada usando 65 secuencias del GenBank (Benson et al. 2011) (Tabla 2). Usamos como guía la filogenia molecular de los Stylommatophora obtenida por Wade et al. (2006). Las secuencias fueron alineadas con ClustalX2 (Larkin et al. 2007) y ajustadas manualmente mediante el programa Bioedit (Hall 1999). El alineamiento fue llevado a cabo por clados, antes del alineamiento general. Se excluyeron del alineamiento regiones extremadamente ambiguas. Priorizamos la búsqueda de segmentos conservados o patrones similares (tres o más nucleótidos); cuando había que tomar una decisión entre transición y transversión, se seleccionó transición. El mejor modelo de substitución nucleotídica para los datos, obtenido con el programa MrModeltest (Nylander 2004), fue GTR, con parámetro de distribución gamma $(\alpha=0,7794)$ y tasa de invariantes
(0,3958). El árbol filogenético para todos los taxa fue obtenido con el método de distancia Neighbour-Joining (NJ) (Saitou \& Nei 1987), utilizando el programa PAUP* 4.0b10 (Swofford 2003), usando un procedimiento heurístico; el soporte de las ramas fue evaluado mediante bootstrap (Felsenstein 1985) con 1000 réplicas; el árbol fue enraizado con Aplysia (Opistobranchia). El análisis filogenético mediante Inferencia Bayesiana fue llevado a cabo usando el programa MrBayes 3.1.2 (Huelsenbeck $\&$ Ronquist 2001) con cuatro Cadenas de Markov Monte Carlo corridas simultáneamente por 25 millones de generaciones, muestreadas cada 2500 generaciones y burn-in de 9000 . Un árbol de consenso y probabilidades posteriores finales fueron calculados usando los árboles restantes. Asimismo, se realizaron análisis filogenéticos para Megalobulimus y para Scolodontidae (Systrophia, S. (Entodina) y Scolodonta) por separado, con sus respectivos grupos externos, pero considerando en el análisis todos los sitios del alineamiento para obtener una mejor resolución dentro de tales clados.

Marcador mitocondrial.- Se usó el marcador mitocondrial 16S rRNA para evaluar las relaciones filogenéticas entre las especies de Megalobulimus, así como su potencial como posible código de barras. Se obtuvieron 25 secuencias de seis especies procedentes de Perú, no existen otras secuencias en el GenBank. Fueron alineadas junto con otras seis secuencias de 
Stylommatophora como grupo externo, las más próximas a Megalobulimus, disponibles en el GenBank (Tabla 2). La matriz de distancias genéticas (no mostrada), con el modelo de substitución nucleotídica Kimura 2-parámetos, así como su análisis mediante UPGMA, fue llevado a cabo con el programa MEGA v.4 (Tamura et al. 2007).

La construcción de árboles filogenéticos se realizó usando los métodos de distancia Neighbour-joining (NJ), máxima parsimonia (MP), máxima verosimilitud (ML) e inferencia bayesiana (IB). Se obtuvo un árbol NJ con el modelo evolutivo de Kimura 2-parámetros y eliminando los gaps sólo en las comparaciones a pares, con bootstrap de 1000 réplicas, mediante el programa MEGA v.4. El análisis con el método de MP fue llevado a cabo con PAUP* $4.0 \mathrm{~b} 10$ utilizando gaps como quinto estado, con bootstrap de 1000 réplicas. Para escoger el modelo evolutivo que mejor se ajuste a los datos, en el análisis filogenético de ML, utilizamos el programa jModeltest (Posada 2008) y el criterio de información de Akaike corregido para muestras pequeñas (AICc); el modelo elegido fue TPM3uf $+\mathrm{I}(0.1320)+\mathrm{G}$ $(\alpha=0.3650)$. Para el análisis bayesiano se utilizó el programa MrModeltest (Nylander 2004) y el criterio de información de Akaike; el modelo elegido fue GTR $+\mathrm{I}+\mathrm{G}$. El análisis ML fue realizado con el programa PhyML (Guindon \& Gascuel 2003) (http://www.atgc-montpellier.fr/phyml). El análisis de IB fue llevado a cabo con MrBayes con cuatro Cadenas de Markov Monte Carlo por 10 millones de generaciones, muestreadas cada 1000 generaciones y burn-in de 9000.

Distribución geográfica.- Para el análisis de las distribuciones se hizo el levantamiento de la información geográfica publicada por Bequaert (1948) y Simone (2006), para Megalo-

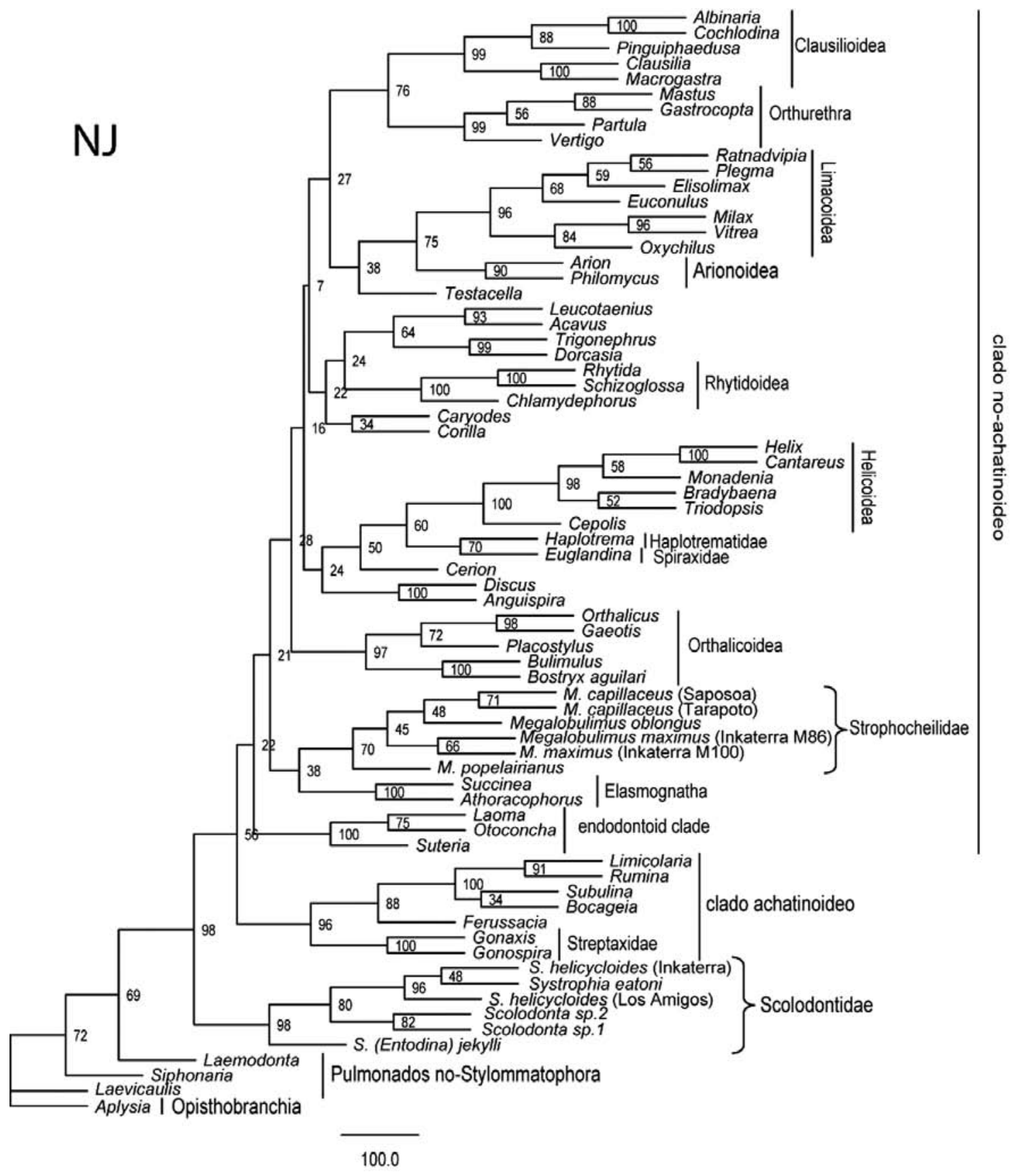

Figura 3. Árbol NJ que muestra la posición evolutiva de dos familias endémicas de América del Sur en la filogenia de los pulmonados Stylommatophora. Strophocheilidae y Scolodontidae están indicadas con llaves. Los clados "achatinoideo" y "no-achatinoideo" son según Wade et al. (2006). Se muestra el soporte de bootstrap en los nodos. La escala representa distancias genéticas en sustituciones de nucleótidos por sitio. 
bulimus (Strophocheilidae), y Ramírez (1993), para Systrophia (Scolodontidae), así como del material usado en el análisis molecular. Se prepararon mapas de distribución geográfica, mediante el programa DivaGis 7.4 (http://www.diva-gis.org), para las especies descritas de Megalobulimus (Bequaert 1948; Salgado \& Coelho 2003; Simone 2006) y Systrophia (Ramírez 1993); para las especies distribuidas fuera de la Amazonia se usaron básicamente sus localidades tipos.

\section{Resultados}

Posición de Megalobulimus y Systrophia en la filogenia molecular de los Stylommatophora.- Usando un marcador nuclear $(>5.8 \mathrm{~S}$ rRNA-ITS2-28S rRNA $<$ ) se obtuvieron cinco secuencias de tres especies de Megalobulimus, y dos de Systrophia helicycloides. En el GenBank se obtuvo una secuencia de Megalobulimus (M. oblongus) de Antigua (Wade et al. 2006) y cuatro de Scolodontidae de Perú (Ramírez et al. 2011). El alineamiento de estas 12 secuencias resultó en 931 sitios con presencia de indels. No hubieron haplotipos compartidos entre las ocho especies analizadas con este marcador nuclear. El alineamiento de estas secuencias con las de distintos representantes de moluscos pulmonados Stylommatophora (Wade et al. 2006; Ramírez et al. 2011) resultó, después de la eliminación de las regiones ambiguas, en 1163 posiciones (estas secuencias incluyen un segmento de aproximadamente $500 \mathrm{pb}$ del gen $28 \mathrm{~S}$ rRNA no amplificado para nuestras especies).

Las siete secuencias nucleares obtenidas formaron grupos monofiléticos con especies de sus respectivas familias, con nodos muy bien soportados (NJ: 70\% y 90\%; IB: 1) (Fig. 3 y 4). Así, las tres especies de Megalobulimus (M. capillaceus, $M$. maximus y $M$. popelairianus) formaron un clado con $M$. oblongus posicionándose como uno de los clados basales dentro del clado "no-achatinoideo" de los Stylommatophora (Wade

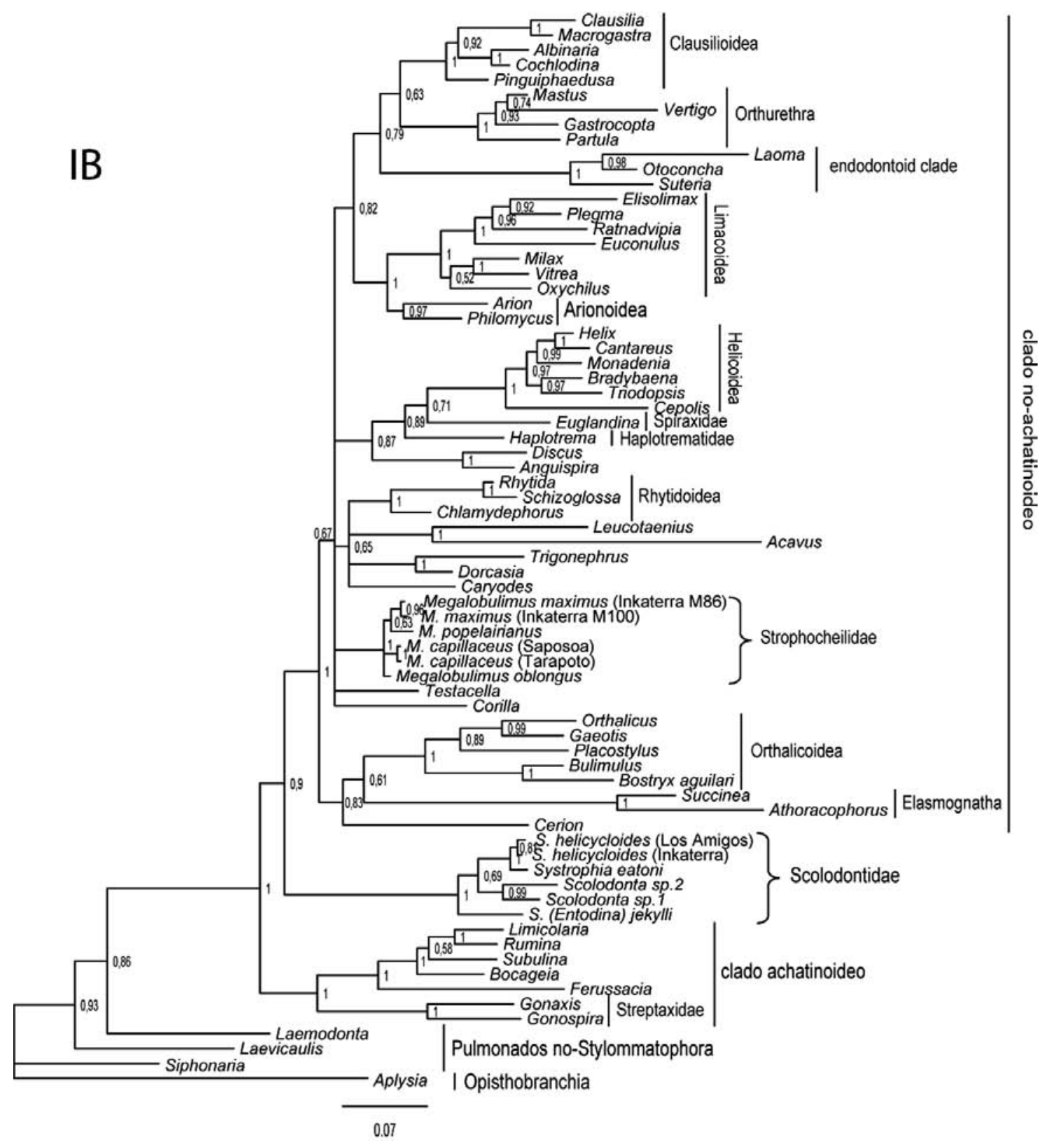

Figura 4. Árbol filogenético obtenido por inferencia bayesiana que muestra la posición evolutiva de dos familias endémicas de América del Sur en la filogenia de los pulmonados Stylommatophora. Strophocheilidae y Scolodontidae están indicadas con llaves. Los clados "achatinoideo" y "no-achatinoideo" son según Wade et al. (2006). El número junto a los nodos indica la probabilidad posterior para el análisis bayesiano. La escala representa distancias genéticas en sustituciones de nucleótidos por sitio. 


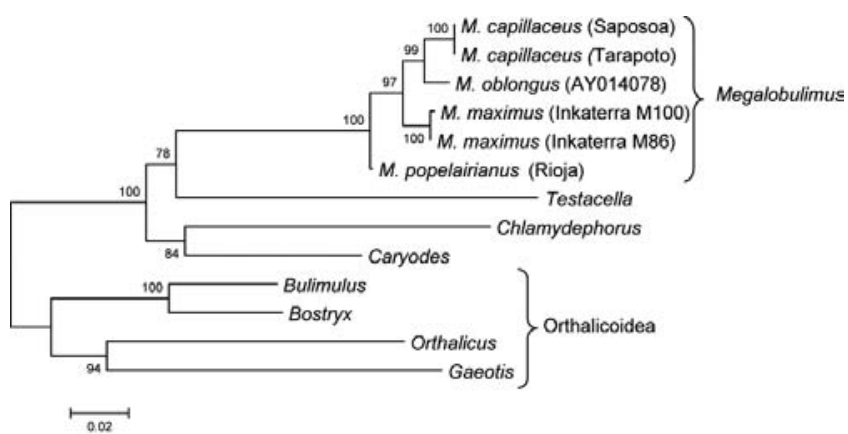

Figura 5. Árbol NJ usando el segmento nuclear completo obtenido con los primers LSU1 y LSU3, donde se muestra una mejor resolución entre las especies de Megalobulimus analizadas (ver Figs. 3-4). El árbol fue enraizado con el clado Orthalicoidea. Se muestra el soporte de bootstrap en los nodos. La escala representa distancias genéticas en sustituciones de nucleótidos por sitio.

et al. 2006). En el caso de las dos secuencias de S. helicycloides, formaron un grupo monofilético con otras especies de la familia Scolodontidae (Ramirez et al. 2011). Los árboles filogenéticos obtenidos por el algoritmo NJ (Fig. 3) así como por IB (Fig. 4), si bien no produjeron topologías idénticas, coincidieron en mostrar a Megalobulimus como uno de los grupos basales del clado "no-achatinoideo" y a Scolodontidae como basal de los Stylommatophora, junto con el clado "achatinoideo".

El análisis filogenético utilizando todos los sitios del alineamiento de las cinco secuencias de Megalobulimus, junto con la de $M$. oblongus y otras tres como grupo externo, obtenidas del GenBank, resulta en una mejor resolución. En el árbol NJ (Fig. 5), el clado Megalobulimus queda altamente sustentado (bootstrap: 100\%), así como la agrupación de $M$. capillaceus con M. oblongus.

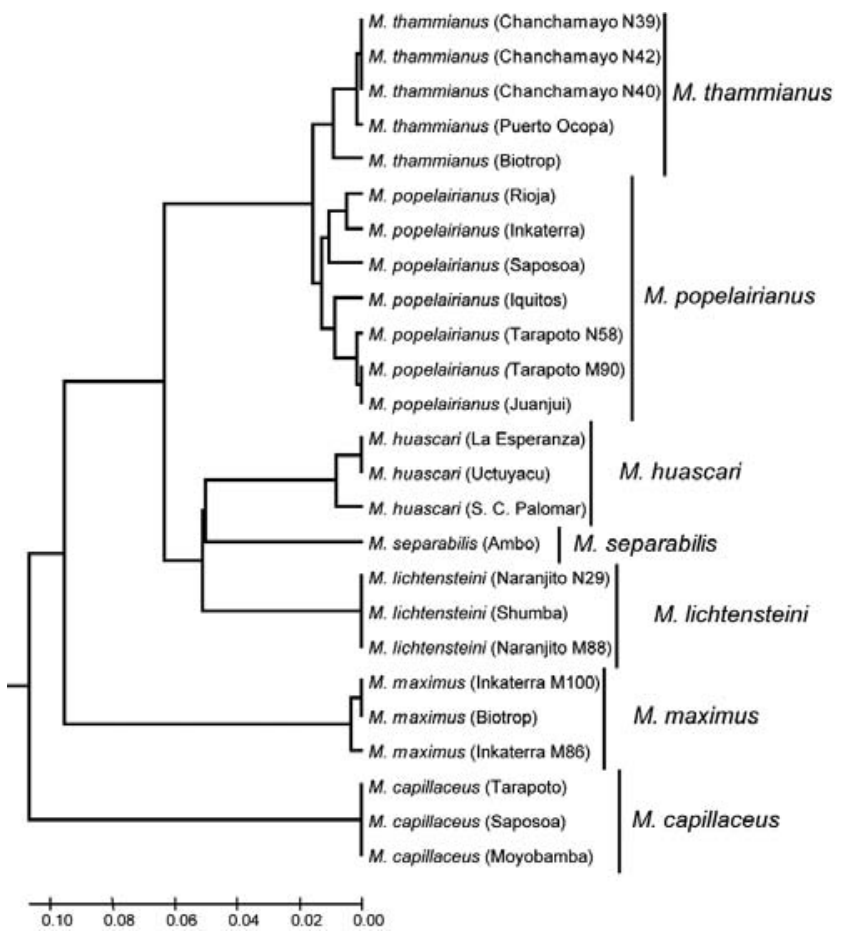

Figura 7. Dendrograma UPGMA de distancias genéticas con el modelo se substitución nucleotídica Kimura 2-parámetros de siete especies de Megalobulimus de la Amazonia occidental. Está basado en un segmento del gen mitocondrial 16S rRNA.

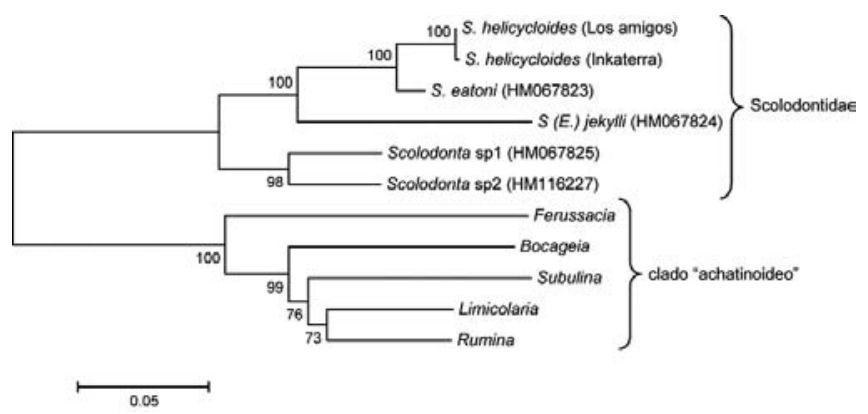

Figura 6. Árbol NJ usando el segmento nuclear completo obtenido con los primers LSU1 y LSU3, donde se muestra una mejor resolución entre las especies de Scolodontidae analizadas (ver Figs. 3-4). El árbol fue enraizado con el clado achatinoideo. Se muestra el soporte de bootstrap en los nodos. La escala representa distancias genéticas en sustituciones de nucleótidos por sitio.

En el caso de las secuencias de Scolodontidae (dos del presente estudio y cuatro del GenBank) analizadas junto con cinco secuencias del clado "achatinoideo" como grupo externo, resultó en una mejor resolución. En el árbol NJ (Fig. 6), las secuencias de Systrophia helycicloides y Systrophia eatoni formaron un grupo monofilético junto con $S$. (Entodina) jekylli, y basal a éstas, las secuencias de Scolodonta spp.

Relaciones evolutivas de las especies del género Megalobulimus de la Amazonia occidental sobre la base del marcador mitocondrial 16S rRNA.- En el presente estudio se obtuvieron 25 secuencias para el marcador molecular del gen mitocondrial

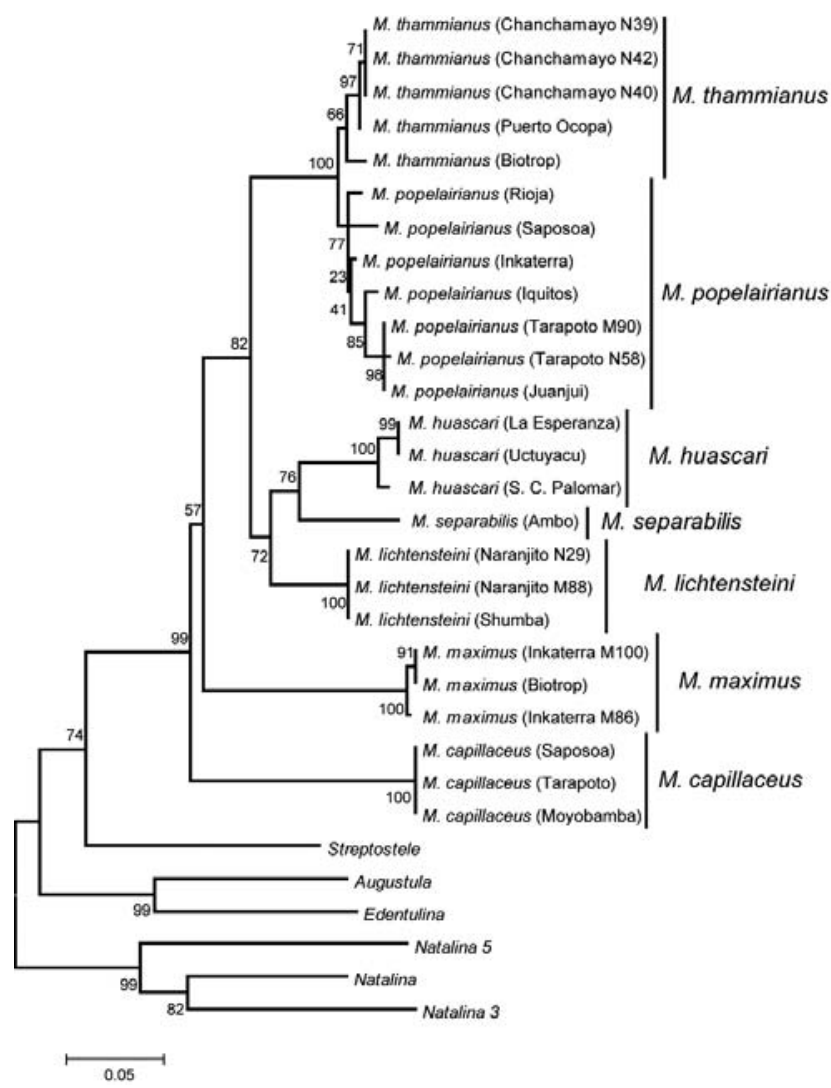

Figura 8. Árbol Neighbour-Joining de siete especies de Megalobulimus de la Amazonia occidental, basado en un segmento del gen mitocondrial 16S rRNA. Se muestra el soporte de bootstrap en los nodos. La escala representa distancias genéticas en sustituciones de nucleótidos por sitio. 


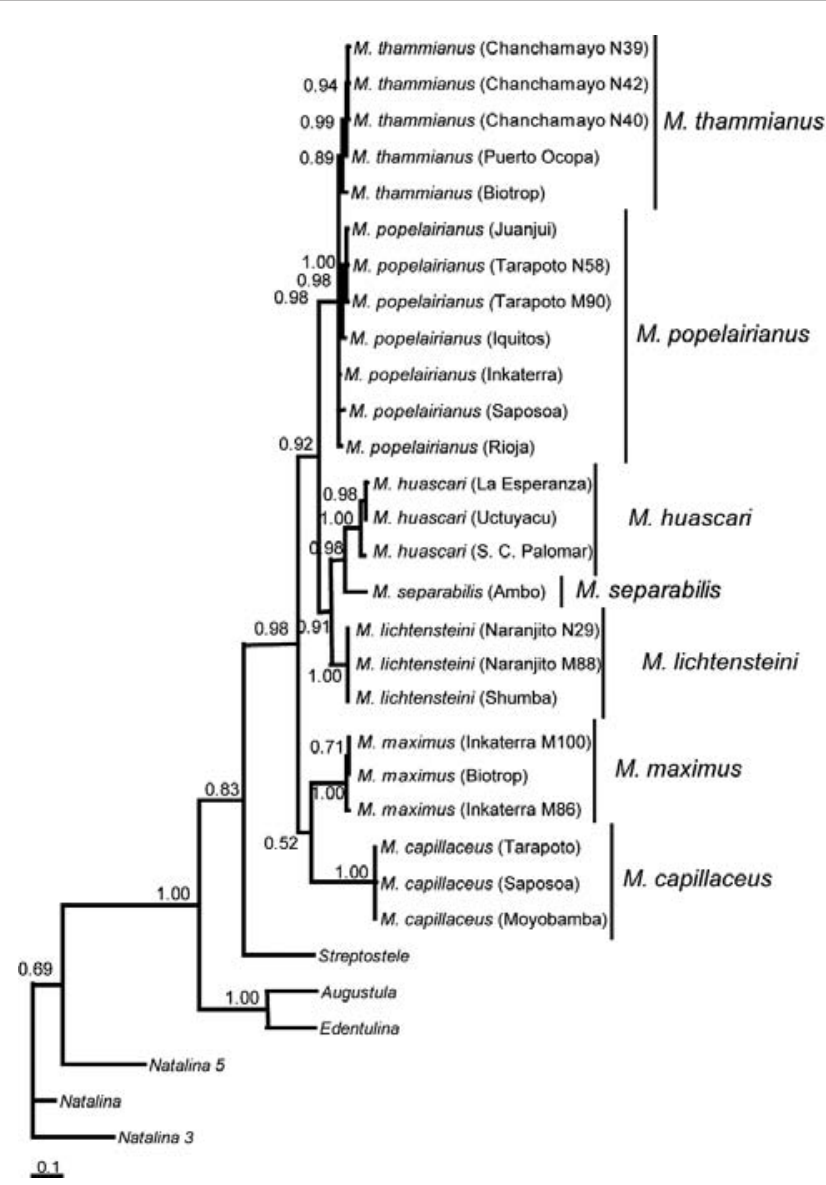

Figura 9. Árbol bayesiano de siete especies de Megalobulimus de la Amazonia occidental, basado en un segmento del gen mitocondrial $16 S$ rRNA. El número junto a los nodos indica la probabilidad posterior para el análisis bayesiano. La escala representa distancias genéticas en sustituciones de nucleótidos por sitio.
16S rRNA, correspondientes a siete especies de Megalobulimus procedentes de Perú (Fig. 1, Tabla 1). En el GenBank no fueron encontradas secuencias de tal marcador para el género Megalobulimus. El alineamiento de las 25 secuencias resultó en 340 sitios con presencia de indels. Se recuperaron 16 haplotipos, sin coincidencias entre especies.

La distancia genética encontrada, con el modelo de substitución nucleotídica K-2p, dentro de cada especie $(0-3,45 \%)$ fue menor que la encontrada entre las especies $(9,49-23,36 \%)$, excepto para $M$. popelairianus y $M$. thammianus. La distancia genética entre estas dos especies está entre 1,85\% y 4,10\%, mucho menor que entre cualquiera de las otras especies analizadas, y cercana a la variación intraespecífica de otras, como por ejemplo de $M$. huascari $(1,54 \%)$ (Fig. 7).

El análisis filogenético de Megalobulimus spp., junto con otros seis taxa como grupo externo, se muestra en las Figuras 8 y 9. Las secuencias obtenidas formaron grupos monofiléticos por especie. Las topologías de los árboles filogenéticos obtenidos mediante MP, ML e IB fueron idénticas (sólo se muestra el de IB) (Fig. 9), topología que coincidió con un clado muy bien sustentado también en el árbol NJ, formado por $M$. huascari, M. separabilis, $M$. lichtensteini, $M$. popelairianus y $M$. thammianus. En el árbol NJ (Fig. 8), M. maximus queda basal al grupo monofilético antes mencionado, y M. capillaceus basal a todas. Por el contrario, en la topología de los árboles obtenidos por MP, ML e IB, $M$. maximus y $M$. capillaceus forman un clado, aunque con bajo soporte (<70\%). En el primer grupo monofilético mencionado, hay dos clados, uno donde $M$. lichtensteini es basal a $M$. huascari y $M$. separabilis, y el otro conformado por $M$. popelairianus y $M$. thammianus (Figs. 8 y 9).

Los ejemplares prodecentes de la localidad tipo de $M$. thammianus (Dpto. Junín, Chanchamayo) quedaron formando un grupo monofilético con buen soporte con un ejemplar de Puerto

Tabla 3. Especies del género Megalobulimus (Strophocheilidae) con distribución en la Amazonia. Se indica los países y altitudes en las que han sido reportadas.

\begin{tabular}{lll}
\hline & Especie & País (altitud) \\
\hline 1. & M. albus (Bland y Binney, 1872) & BRASIL (60m). VENEZUELA (915m). TOBAGO (89m). \\
2. & M. capillaceus (Pfeiffer, 1855) & PERÚ (300-870m). BOLIVIA (300-1917m). \\
3. & M. carrikeri (Pilsbry, 1930) & PERÚ (1600-2140 m) \\
4. & M. conicus (Bequaert, 1948) & BRASIL (460-463m) \\
5. & M. huascari (Tschudi, 1852) & PERÚ (1000-1797m) \\
6. & M. indigens (Fulton, 1914) & PERÚ \\
7. & M. intertextus (Pilsbry, 1895) & BOLIVIA (228-296m). BRASIL (119m). URUGUAY (23m). \\
8. & M. leonardosi (Morretes, 1952) & BRASIL (220m). \\
9. & M. leucostoma (Sowerby, 1835) & PERÚ (1070-2300m). BOLIVIA (4519m). \\
10. & M. lichtensteini (Albers, 1854) & PERÚ (489-1600m). \\
11. & M. maximus (Sowerby, 1825) & BRASIL (70-500m). BOLIVIA (251-560m). PERÚ (198-690m). \\
& & COLOMBIA: Orinoquia (467 m), Andina (352-1200 m), Caribeña (0-150 m). VENEZUELA (850- \\
12. & M. oblongus (Müller, 1774) & 2,220 m). BRASIL: Amazonia (90 m), Cerrado (678 m). BOLIVIA (200-400 m). ARGENTINA (450 m). \\
& & PARAGUAY (124 m). Islas del Caribe. \\
13. & M. oosomus (Pilsbry, 1895) & BRASIL (37-20m) \\
14. & M. popelairianus (Nyst, 1952) & ECUADOR: Occidente (200-655m), Oriente (879-1220m). COLOMBIA: Amazonia (250-605m), \\
15. & M. santacruzii (Orbygny, 1835) & BOLinoquia (350 m), Andina (1000-1750m). PERU (112-690m). \\
16. & M. senezi (Jousseaume, 1884) & COLOMBIA \\
17. & M. separabilis (Fulton, 1903) & PERÚ (2000-2010m) \\
18. & M. thammianus (Martens, 1876) & PERU (200-1488m). COLOMBIA (442m). Ecuador (1000-2000m). \\
19. & M. vestitus (Pilsbry, 1926) & BOLIVIA (300-400m). PERÚ (1600m). BRASIL (1041m) \\
\hline
\end{tabular}



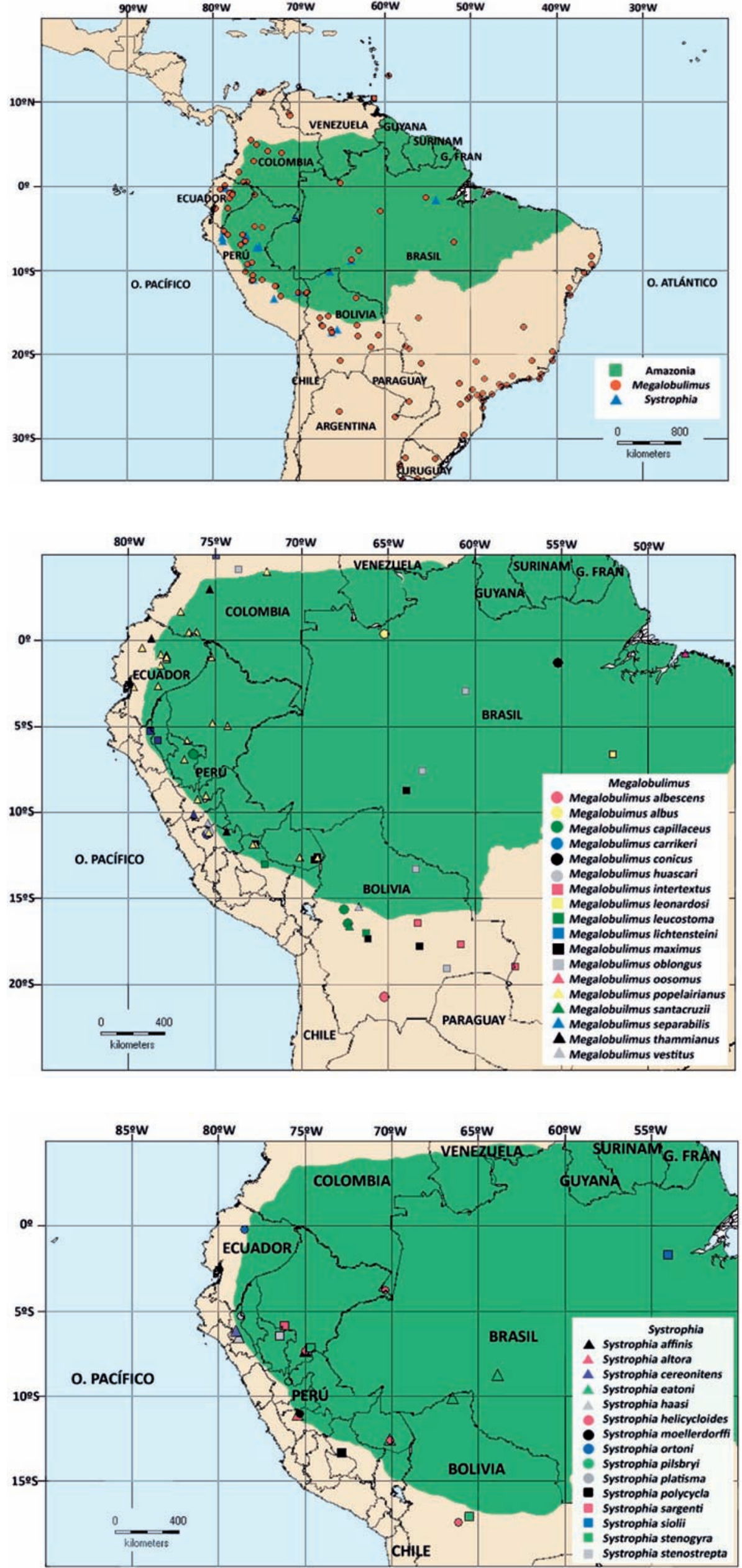

Figura 10. Distribución geográfica del género Megalobulimus (Strophocheilidae) y Systrophia (Scolodontidae).
Figura 11. Distribución geográfica de especies del género Megalobulimus (Strophocheilidae) con distribución en la Amazonia.
Figura 12. Distribución geográfica de las especies conocidas del género Systrophia (Scolodontidae). 
Tabla 4. Especies del género Systrophia (Scolodontidae) y su distribución por países y altitudinal.

\begin{tabular}{|c|c|c|c|}
\hline & Especie & País & Altitud (m) \\
\hline 1. & S. affinis (Pilsbry, 1900) & Perú & $120-1000$ \\
\hline 2. & S. altora Weyrauch, 1967 & Perú & $2100-2600$ \\
\hline 3. & S. calculina (Pfeiffer, 1868) & América Del Sur & \\
\hline 4. & S. eatoni Baker, 1913 & Brasil; Perú; Bolivia & $100-300$ \\
\hline 5. & S. haasi Weyrauch, 1960 & Perú & 2100 \\
\hline 6. & S. helicycloides (Orbigny, 1835) & Bolivia; Perú; Colombia & Perú (186 - 1600) / Bolivia (180-400) / Colombia (40-150) \\
\hline 7. & S. impressa Haas, 1951 & América Del Sur & \\
\hline 8. & S. moellerdorffi Rolle, 1904 & Perú & $1400-3000$ \\
\hline 9. & S. ortoni (Crosse, 1871) & Ecuador; Perú & Ecuador (2818) \\
\hline 10. & S. pilsbryi Weyrauch, 1958 & Perú & 670 \\
\hline 11. & S. platysma Haas, 1951 & Perú; Bolivia & Perú 1400/ Bolivia 1000 \\
\hline & S. polycycla (Morelet, 1860) & Perú & 3000 \\
\hline 13. & S. sargenti (Pilsbry, 1900) & Perú & 100 \\
\hline 14. & S. siolii Haas, 1955 & Brasil & 38 \\
\hline & S. stenogyra (Pfeiffer, 1854) & Perú; Brasil & Perú $(870$ - 1600) \\
\hline & S. stenogyra zischkai Blume, 1955 & Bolivia & 2000 \\
\hline & S. stenostrepta (Pfeiffer, 1856) & Perú & $300-600$ \\
\hline & S. stenostrepta declinata (Pilsbry, 1900) & Perú & \\
\hline 17. & S. systropha $($ Albers, 1854$)=$ S. cereonitens Haas, 1951 & Perú & $700-1200$ \\
\hline
\end{tabular}

Ocopa (Oco) y otro de Madre de Dios (Biot). Por el contrario, las secuencias correspondientes a $M$. popelairianus no formaron un clado con igual soporte en las filogenias obtenidas con los distintos métodos filogenéticos utilizados.

Distribución geográfica de Megalobulimus spp. en la Amazonia.- Las 67 especies conocidas del género Megalobulimus (Bequaert 1948; Salgado \& Coelho 2003; Simone 2006), se encuentran en regiones tropicales y subtropicales de América del Sur, en Colombia, Venezuela, Ecuador, Perú, Bolivia, norte de Argentina, Paraguay, Uruguay y Brasil, dos especies llegan a las islas del Caribe (Fig. 10). En la Amazonia se encuentran registradas 19 especies (Tabla 3), distribuidas principalmente en la Amazonia ocidental, apenas tres especies se dan solamente en la Amazonia oriental (Brasil) ( $M$. conicus, M. leonardosi y $M$. oosomus) (Fig. 11). El Perú alberga el mayor número especies endémicas (M. carrikeri, M. huascari, $M$. indigens, $M$. lichtensteini y $M$. separabilis), Bolivia tiene una (M. santacruzii), así como Colombia (M. senezi). Otras especies se encuentran en dos paises, como M. capillaceus y M. leucostoma (Perú y Bolivia), M. maximus y $M$. vestitus están en tres (Perú, Bolivia y Brasil), M. popelairianus y M. thammianus (Perú, Ecuador y Colombia), M. albus (Brasil, Venezuela y Tobago) y M. intertextus (Bolivia, Brasil y Uruguay). La especie de más amplia distribución es $M$. oblongus que se encuentra en Colombia, Venezuela, Brasil, Bolivia, Argentina, Paraguay e islas caribeñas.

Altitudinalmente, se encuentran desde el nivel del mar hasta los $2220 \mathrm{~m}$, con un registro para M. leucostoma a $4519 \mathrm{~m}$ (Bolivia, Totolima). Cuatro especies se encuentran por debajo de los $500 \mathrm{~m}$ (M. intertextus, M. conicus, $M$. leonardosi y $M$. oosomus), tres por debajo de los $1000 \mathrm{~m}$ (M. maximus, $M$. capillaceus y $M$. albus), siete llegan hasta $1600-2000 \mathrm{~m}$ (M. vestitus, $M$. huascari, M. lichtensteini, M. popelairianus, M. thammianus, M. santacruzii y $M$. capillaceus -en Bolivia-), y las que van más allá de los $2000 \mathrm{~m}$ de altitud son $M$. leucostoma, M. carrikeri, $M$. separabilis y $M$. oblongus. Dos especies descritas únicamente para Perú (M. indigens) y para Colombia $(M$. senezi) no tienen localidad específica.
Las especies endémicas de Perú se encuentran en las vertientes orientales de los Andes, entre 489 y $2140 \mathrm{~m}$ de altitud, en los departamentos de Junín, Huánuco y Cajamarca-Amazonas. Las de Bolivia se encuentran entre 1200 - 1600 m, en los departamentos de Chuquisaca y La Paz. Las especies endémicas de la Amazonia de Brasil están a 20-200 m de altitud, en la región oriental.

M. popelairianus, que posee la concha de mayor tamayo (163 $\mathrm{mm}$ ), es la especie de más amplia distribución en la Amazonia. Es encontrada en Perú en bosques de la vertiente oriental de los Andes y selva baja (112-690 m); en Ecuador (Gram et al. 2009) se encuentra tanto en bosques del Occidente (200-655 m) como del Oriente (879-1220 m), y en Colombia (Hernández-Camacho 1992) ha sido registrada en las regiones de Amazonia (250-605 m), Orinoquia (350 m) y Andina (1000-1750 m) (Tabla 3).

Distribución geográfica de Systrophia spp.- La familia Scolodontidae, que está constituida por caracoles terrestres carnívoros, es endémica del neotrópico, con mayor distribución en América del Sur. Systrophia es uno de sus géneros y está practicamente restringida a la Amazonia occidental (Figs. 10 y 12), encontrada en ambientes boscosos, entre la hojarasca. De las 17 especies 11 están restringidas a Perú. De las otras especies, S. eatoni ha sido registrada para el sur de Perú (Madre de Dios), Bolivia y Brasil (Ríos Madeira y Mamoré), S. helicycloides (Fig. 2) para Bolivia, Perú y Colombia, S. siolii para Brasil (Pará) y S. stenogyra en Perú y Bolivia.

La mayoría de las especies (10) son encontradas hasta un máximo de $1600 \mathrm{~m}$ de altitud, y cinco especies llegan a altitudes entre 2000 y $3000 \mathrm{~m}$ (Tabla 4).

\section{Discusión}

Clasificación de las familias de gastrópodos Neotropicales: Strophocheilidae y Scolodontidae.- Megalobulimus (Strophocheilidae) y Systrophia (Scolodontidae) pertenecen a familias de caracoles terrestres endémicas de América del Sur, con origen gondwánico, y muy antiguas dentro de los pulmonados Stylommatophora (Leme 1975; Parodiz 1982). La familia 
Strophocheilidae está considerada dentro de la superfamilia Acavoidea Pilsbry 1895 (Hausdorf \& Bouchet 2005), cuyos representantes se distribuyen en Amércia del Sur, suroccidente de África, Madagascar, las Seychelles, Sri Lanka y el oriente de Australia (Emberton 1990). Wade et al. (2006) usaron una sola secuencia en la filogenia nuclear de los Stylommatophora, la que quedó agrupada con la única secuencia de Corilla (familia Corillidae) en los árboles NJ (46\%) e IB $(0,83)$; nosotros hemos usado seis secuencias de Megalobulimus, las que formaron un grupo monofilético fuertemente sustentado (NJ: 70\%; IB: 1 ), pero no formó un clado con sustento con ninguna otra secuencia. El resultado de Wade et al. (2006) puede deberse al artefacto de "long branch atraction", lo cual puede ser corregido incrementando el número de secuencias (Bergsten 2005); no obstante ello, no se pudo confirmar la posición de las especies de Megalobulimus de la Amazonia occidental dentro de la superfamilia Acavoidea, aunque es claramente un miembro del clado "no-achatinoideo" (Figs. 3 y 4).

Por el contrario, las relaciones evolutivas de los caracoles terrestres carnívoros de la familia Scolodontidae Baker, 1925 no han tenido mayor consenso; en la última clasificación de familias de gastrópodos ha quedado dentro de la superfamilia Rhytidoidea Pilsbry, 1893 (Hausdorf \& Bouchet 2005). La filogenia con el marcador molecular nuclear no respalda esa posición ni su inclusión en el clado "no-achatinoideo", al contrario de lo que sucedió con Megalobulimus; los géneros Systrophia y Scolodonta formaron un clado monofilético fuertemente sustentado e independiente de los dos clados formales de los Stylommatophora (Wade et al. 2006), "achatinoideo" y "no-achatinoideo" (Figs. 3 y 4). En el árbol filogenético NJ (Fig. 3), el clado Scolodontidae resulta basal, por dabajo del clado "achatinoideo", mientras que en el de inferencia bayesiana, los "achatinoideos" están en posición basal, por lo que más bien deberían considerarse tres clados en la filogenia de los pulmonados Stylommatophora (Ramírez et al. 2011).

Endemismos en la Amazonia Occidental.- Las especies de caracoles terrestres de las familias Strophocheilidae y Scolodontidae son endémicas de América del Sur, con parientes cercanos en África (Parodiz 1982). Strophocheilidae está relacionada con la familia Dorcasiidae, presentes en el sur de África (Leme 1975). Scolodontidae había sido relacionada a diversas familias, hasta que su inclusión en la filogenia molecular de los Stylommatophora la mostró como un grupo cercano al clado achatinoideo, muchos de ellos presentes sólo en África. Los géneros Systrophia (Scolodontidae) y Megalobulimus (Strophocheilidae) están bien representados en la Amazonia. Las especies del género Systrophia son habitantes conspícuos de la Amazonia occidental, con endemismos importantes en Perú; están restringidas al área endémica denominada Amazonia suroccidental (SWAm) (Sigrist \& Carvalho 2009). Por el contrario, el género Megalobulimus tiene amplia distribución, ocupando regiones tropicales y subtropicales. En la Amazonia, se encuentran más restringidas al occidente, en el área endémica SWAm; la especie $M$. popelairianus tiene más amplia distribución tanto en altitud como en latitud, además ha sido reportada también para el área endémica de la Amazonia Norte (NAm) (Fig. 11). Megalobulimus oblongus ha sido reportada en las dos otras áreas endémicas de la Amazonia, la suroriental y la norteña (Sigrist \& Carvalho 2009), pero también está en el norte de Colombia (Götting 1978) y Venezuela (Baker 1926) e islas caribeńas (Bequaert 1948) (Fig. 11).
En el departamento de Junín (Perú) se encuentra la mayor diversidad del Género Megalobulimus (M. huascari, M. carrikeri, $M$. popelairianus y $M$. thammianus), donde se encuentra uno de los mayores centros de endemismos en Perú, la unidad Chanchamayo (Lamas 1982). Es importante resaltar que en el análisis filogenético basado en el gen mitocondrial $16 \mathrm{~S}$ rRNA, las tres especies endémicas de Perú (M. huascari, $M$. separabilis y $M$. lichtensteini) formaron un grupo monofilético, donde las especies $M$. huascari y $M$. separabilis son hermanas. Estas dos especies también se encuentran más próximas geográficamente (Dptos. Junín y Huánuco, respectivamente) que la basal $M$. lichtensteini presente en el norte de Perú (Dptos. Cajamarca y Amazonas). Estos resultados dan más soporte a la generalización de que la Amazonia occidental y los bosques tropicales de los Andes están entre las mayores áreas de endemismos (Moritz et al. 2000; Young 2007; Pacheco et al. 2009), y los estudios moleculares están dando indicios de que albergan la mayor concentración de especies endémicas de reciente evolución en relación a la parte baja de la Amazonia (Moritz et al. 2000).

La familia Scolodontidae tiene amplia distribución en América del Sur, y uno de sus géneros, Systrophia, es endémica de la Amazonia occidental, con la mayor diversidad en las vertientes orientales de los Andes en Perú. Es interesante notar que hay una coincidencia en la distribución de Systrophia eatoni (Fig. 12) con la de Megalobulimus maximus (Fig. 11), las cuales están reportadas para las selvas del sur oriente de Perú, Bolivia y Brasil (Rondonia). Tal distribución coincide con la unidad biogeográfica Inambari de Lamas (1982), identificada sobre la base de especies endémicas de mariposas, delimitada en el norte por el río Purús (Perú), extendiéndose en el noroeste de Bolivia y suroeste de Brasil.

\section{Sistemática y Código de barras de ADN}

Megalobulimus spp. de la Amazonia.- En el análisis filogenético de siete de las 11 especies de Megalobulimus presentes en Perú, todas las secuencias 16S rRNA usadas se agruparon monofiléticamente por especie, con buen soporte bootstrap y probabilidad posterior (Figs. 8 y 9). La taxonomía de Megalobulimus ha sido considerada como muy confusa debido a la gran variación que presentan sus conchas (Leme 1973), que era todo lo que se usaba para su identificación, cuando Bequaert (1948) hizo la revisión de la familia Strophocheilidae. Sobre esa base, el autor juntó especies nominales como sinónimas o considerándolas subespecies. Así, consideró a M. huascari (Tschudi, 1852) como una subespecie de M. maximus (Sowerby, 1825), lo cual no es sustentado por nuestros resultados, donde las secuencias 16S rRNA de $M$. huascari formaron un clado filogenéticamente lejano de M. maximus. Por otro lado, Bequaert (1948) consideró a $M$. popelairianus (Nyst, 1845), el caracol más grande del género, "muy cercanamente relacionada a $M$. maximus", tanto que la dejaba "provisionalmente" como una especie distinta. Ambas especies son conocidas en Perú con el nombre vulgar de "congompe", donde la primera está ampliamente distribuida, principalmente en la selva baja, mientras que la segunda ha sido reportada sólo para Madre de Dios. Nuevamente, el análisis filogenético muestra que $M$. popelairianus no sólo es una especie distinta sino que tampoco está cercanamente relacionada a $M$. maximus. La concha de $M$. popelairianus es muy variable, lo que llevó a Martens (1876) a describir otras tres "variedades" (thammianus, dohrnianus y connectens), al presente consideradas 
como sinónimas de M. popelairianus (Simone 2006). Ejemplares del complejo de especies $M$. popelairianus colectados en distintas localidades del Perú formaron un grupo monofilético, en donde los de la localidad tipo de $M$. thammianus (Martens, 1876), "Chanchamayo" (Junín, Perú), formaron un clado bien sustentado junto con otros dos ejemplares de Madre de Dios, lo que podría respaldar a $M$. thammianus como una especie válida. Para definir el verdadero estatus taxonómico de $M$. popelairianus y $M$. thammianus se requiere de un análisis más extensivo, donde se incluya ejemplares procedentes de la amplitud de sus distribuciones geográficas, ambas especies están reportadas también para Ecuador y Colombia (Tab. 3).

La concha de M. capillaceus (Pfeiffer 1855) tiene el peristoma rojo, por lo que ha sido confundida con otras dos especies que también lo presentan (M. oblongus y $M$. separabilis) (Bequaert 1948). Recientemente, Borda (2011) deslindó este problema taxonómico mediante análisis del sistema reproductor, encontrando que son especies válidas, con $M$. separabilis muy diferente de $M$. capillaceus y $M$. oblongus; estas dos últimas presentan sinapomorfías en el epifalo y en el oviducto libre. Asimismo, que lo reportado para Bolivia podría no corresponder a $M$. capillaceus. Nosotros hemos encontrado, mediante la filogenia molecular sobre la base del rADN nuclear, que efectivamente $M$. capillaceus y $M$. oblongus forman un grupo monofilético (Figs. 3-5), y que, con el análisis filogenético sobre la base del marcador mitocondrial $16 \mathrm{~S}$ rRNA, M. capillaceus está totalmente alejada de M. separabilis (Figs. 8-9).

Una identificación rápida y segura de las especies es altamente necesaria, por bioseguridad, autenticación alimentaria, contra comercio ilegal, etc., lo que ahora es posible gracias a la biología molecular (Wong \& Hanner 2008; Ferri et al. 2009). La identificación taxonómica de especies ampliamente usadas en alimentación humana es primordial, aun fuera de los ámbitos científicos. La identificación taxonómica de las especies de moluscos comercializados a nivel local, al momento actual requieren de una carta de presentación que pueda elevar su credibilidad para el biocomercio a nivel internacional, como sucede con peces, por ejemplo (Handy et al. 2011). La biología molecular está ayudando grandemente en esta tarea, al permitir caracterizar a las especies mediante código de barras de $\mathrm{ADN}$, al igual que los códigos de barras de los productos en los supermercados; un segmento del gen mitocondrial de la citocromo oxidasa $\mathrm{C}$ subunidad I (COI) ha sido propuesto como el marcador de estándar global para animales (Hebert et al. 2003a, b; Hebert \& Gregory 2005; Hajibabaei et al. 2007). Sin embargo, se ha encontrado que el gen 16S rRNA es tan bueno o mejor que el COI, para algunos grupos como anfibios (Vences et al. 2005) e Hydrozoa (Cnidaria) (Moura et al. 2008). Asimismo, para moluscos se había encontrado que el gen $16 \mathrm{~S}$ rRNA proveía suficiente variación intraespecífica como para también ser usado en estudios poblacionales, fuera de su comprobada eficiencia para resolver relaciones filogenéticas entre especies o categorías taxonómicas superiores (Chiba 1999; Ramirez et al. 2009), y a la fecha ya ha sido utilizado específicamente como código de barras en bivalvos de la familia Pectinidae (Feng et al. 2011) y en babosas del género Arion (Barr et al. 2009). Una de las razones que se aduce para respaldar al COI como estándar global es que existen primers universales para su amplificación por PCR (Folmer et al. 1994); no obstante, para los bivalvos Pectinidae no amplificó en lo absoluto (Feng et al. 2011). En el caso particular de caracoles del género Megalobulimus, la amplificación del marcador 16S rRNA mostró 100\% de eficacia, no así el COI (Congrains 2010; R. Ramírez, obs. pers.). Las especies de Megalobulimus aquí analizadas tuvieron haplotipos 16S rRNA privados y formaron grupos monofiléticos, con distancias intraespecífica menores a las interespecíficas, conformando código de barras para ellas. Tales distancias fueron menores entre $M$. popelairianus y $M$. thammianus, aunque formaron grupos monofiléticos recíprocos.

Systrophia (Scolodontidae) .- Entre los géneros de la familia Scolodontidae, Systrophia sensu estricto puede ser identificado de inmediato por su concha, así como Drepanostomella y Guestieria. En una filogenia morfológica de la familia Systrophiidae (=Scolodontidae) (Ramírez 1993, 1995), Systrophia s.s. es grupo hermano de $S$. (Systrophiella) los que forman un grupo monofilético con Wayampia [=Scolodonta (Hausdorf 2006)] y Happia. Entodina no fue incluida en el análisis por falta de material con parte blanda, así que quedó en su mismo estatus taxonómico, un subgénero de Systrophia según Vaught (1989). En la filogenia molecular con el marcador nuclear obtenida en el presente trabajo, la especie $S$. (Entodina) jekylli formó un clado con las especies $S$. (Systrophia) helicycloides y S. (S.) eatoni. Sin embargo se necesita incluir en la filogenia muchas más secuencias de Entodina, y otros géneros para entender las relaciones evolutivas dentro de la familia Scolodontidae.

La identificación por medio del código de barras de ADN con el marcador estándar, un segmento del COI, ha sido aplicada en Systrophia helicycloides (Romero \& Ramírez 2011). Las distancias genéticas intraespecíficas encontradas sobrepasaron la distancia genética de $2 \%$ propuesta para discriminar especies (Hebert et al. 2003a). S. helicycloides presentó dos grupos de haplotipos con distancias genéticas intraespecíficas mayores a $4 \%$, pero los especímenes correspondientes no mostraron diferencias morfológicas; tal resultado fue concidente con el marcador mitocondrial 16S rRNA (Romero 2010). Esta es una prueba más de que aún falta mucho por hacer en el estudio de diversidad molecular de moluscos, y en general de invertebrados, especialmente de la Amazonia, para poder hacer generalizaciones en relación a código de barras de $\mathrm{ADN}$, como ya se hace para muchos grupos de vertebrados.

\section{Usos y amenazas}

Megalobulimus es muy apreciado por el poblador amazónico, y en el Perú está incluido en su culinaria (Ríos et al. 1973; INIA 2006), son vendidos en los mercados de ciudades de la Amazonia peruana, siendo los más representativos los de Iquitos (Dpto. Loreto) (Castro et al. 1976) y Tarapoto (Dpto. San Martín) (Ramírez y Cáceres 1991). También se comercializa esporádicamente en el mercado de "La Parada" (Lima), donde se ha observado la venta de $M$. popelairianus y M. lichtensteini, por las supuestas bondades de la baba de caracol sobre la piel; por motivos semejantes se ha observado la comercialización de M. oblongus en el mercado de Medellín (Colombia) (M. Restrepo, com. pers.).

El consumo de caracoles del género Megalobulimus ya había sido reportado en 1895 por Pilsbry para Ecuador. Pero también se han encontrado evidencias de su uso por pobladores prehispánicos, no sólo de la amazonia, sino también de Ecuador (Stahl 2005), Perú (Rodriguez 2006), y Brasil (Mello \& Coelho 1989), inclusive de que fue transportado a la costa del Perú hace 
más de 5 mil años, como dan fe los restos encontrados en Caral (Shady 2000).

Otro uso común que le dan a Megalobulimus spp., así como a otras especies de moluscos terrestres, es para curar problemas respiratorios, algo muy difundido en la zona de Chanchamayo, Perú (Ramírez et al. 2003); en Brasil, caracoles de la especie $M$. oblongus son usados específicamente para curar el asma (Alves \& Dias 2010; Barbosa \& Alves 2010).

Las conchas de Megalobulimus y otras especies de moluscos han sido y continuan siendo usados como ornamentos o como elemento para la confección de artesanías (Brownrigg 1996). En la guarnición de Pantoja (Perú, Loreto), el techo abovedado de una gruta para la Virgen María está cubierto completamente con conchas de congompe de la especie $M$. popelairianus, la más grande de la Amazonia (R. Ramírez, obs. pers.).

El uso milenario de estas especies se da por simple extracción de su medio natural (Castro et al. 1976; Ramírez \& Cáceres 1991). Se han realizado intentos para su crianza (Rengifo et al. 2004) y manejo (Campoverde 1992), pero hasta el momento no se conoce que se haya logrado su producción comercial. La mayoría de especies de Megalobulimus habitan en el suelo con abundante hojarasca, en áreas boscosas, y al parecer no se adaptan facilmente a condiciones de cautiverio, sin embargo $M$. capillaceus en Perú (Ramírez \& Cáceres 1991), y M. oblongus en Colombia (Götting 1978) y Venezuela (Baker 1926), podrían tener condiciones para ser cultivadas por vivir cerca al hombre.

La extracción indiscriminada de congompes está causando la disminucion de sus poblaciones, como lo reconocen los mismos pobladores; a esta amenaza se suma la destrucción del hábitat, no sólo por la extracción de madera sino también por el crecimiento de las ciudades (García-Villacorta 2009), y la mineria del oro como en la amazonia de Madre de Dios (Perú). La destrucción de la Amazonia es irreversible (Vieira et al. 2008) y con ello la potencial extinción de muchas especies endémicas y recursos naturales.

\section{Agradecimientos}

El material biológico utilizado en el presente trabajo procede de colectas realizadas como parte de proyectos de investigación de R. Ramírez, en el Instituto de Investigación en Ciencias Biológicas "Antonio Raimondi" de la Facultad de Ciencias Biológicas, y en el Museo de Historia Natural, financiados por la Universidad Nacional Mayor de San Marcos (VRI PEM2007B28; VRI-CSI No 061001015, 071001045, 081001071, 091001041, 101001091 y 111001241), CONCYTEC (1984 1987 y 1994), la Asociación para la Conservación de la Cuenca Amazónica (ACCA) (www. acca.org.pe) y la ONG Inka Terra Asociación (ITA) (http://www. itaperu.org). Agradecemos al Dr. W.E.Duellman, Director del Programa BIOTROP, por el apoyo brindado en Cuzco Amazónico (ahora INKATERRA); a F. Encarnación y C. Ascorra (Bioamaz) en Aguas Negras; a N. Pitman, C. Ituarte, y M.G. Cuezzo en el CICRA; a J. Purisaca, H. Méndez y G. Villarroel por el apoyo logístico en INKATERRA. También a C. Calderón, A. Ruiz, T. Robalino, por su asistencia de campo en San Martín, y a las familias Zúñiga, Huamaní y Castro en Chanchamayo. Estamos muy agradecidos por conseguir congompes a E. Correa, J. Mesías, C. Díaz y S. Vaca; y a M. Quispe, D. Fernández y P. Matos por el cuidado de los caracoles vivos. Al INRENA por los permisos para trabajo en áreas reservadas.

\section{Literatura citada}

Abad R. 1996. Therapeutic and cosmetic compositions for treatement of skin. United States Patent. Patent No 5,538,740.

Alves R. \& T. Dias. 2010. Usos de invertebrados na medicina popular no Brasil e suas implicações para conservação. Tropical Conservation Science 3 (2): 159-174.

Baker H. 1925. Agnathomorphous aulacopoda. Nautilus 38: 86-89.

Baker H.B. 1926. The Mollusca collected by the University of Michigan-Williamson Expedition in Venezuela, Part IV. Occasional Papers, University of Michigan Museum of Zoology 167: 1-65.

Barbosa J. \& R. Alves. 2010. “Um chá de que?”-Animais utilizados no preparo tradicional de bebidas medicinais no agreste Paraibano. BioFa 4 (2): 1-12.

Barr N., A. Cook, P. Elder, J. Molongoski, et al. 2009. Application of a DNA barcode using the 16SrRNA gene to diagnose pest Arion species in the USA. J. Moll. Stud. 75: 187-191.

Bequaert, J.C. 1948. Monograph of the Strophocheilidae, a Neotropical family of terrestrial mollusks. Bull. Mus. comp. Zool. 100 (1): 1-210.

Benson D.A., I. Karsch-Mizrachi, D.J. Lipman, et al. 2011. GenBank. Nucleic Acids Research 39: D32-D37.

Bergsten J. 2005. A review of long-branch attraction. Cladistics 21: 163-193.

Borda V. 2011. Especies de Megalobulimus (Mollusca, Megalobulimidae) con peristoma rojo del Perú: discriminación, estatus taxonómico y descripción de una nueva especie. Tesis para optar el Título Profesional de Biólogo. Facultad de Ciencias Biológicas, Universidad Nacional Mayor de San Marcos.

Borda V., R. Ramírez \& P. Romero. 2010. Glándula pediosa de moluscos terrestres y sus implicancias evolutivas, con énfasis en Megalobulimus. Revista Peruana de Biología 17 (1): 43-52.

Breure A.S.H., D.S.J. Groenenberg \& M. Schilthuizen. 2010. New insights in the phylogenetic relations within the Orthalicoidea (Mollusca: Gastropoda), based on $28 \mathrm{~S}$ sequence data. Basteria 74: 25-31.

Brownrigg L.A. 1996. Categories of faunal and floral Economic resources of the native communities of the Peruvian amazon in 1993. Journal of ethnobiology 16 (2): 185-211.

Bruggen A.C. van. 1995. Biodiversity of the mollusca: time for a new approach. In: A.C.van Bruggen, S.M. Wells and Th.C.M. Kemperman, eds. Biodiversity and conservation of the Mollusca. Eleventh International Malacological Congress, Siena, Italy 1992. Backhuys, Oegstgeest- Leiden, the Netherlands. Pp. 1-18.

Campoverde L. 1992. Posibilidades de Manejo del Caracol Terrestre Megalobulimus maximus como recurso proteínico en San Martín. Tesis Magíster Scientiae. Lima - Perú. 83 pp.

Castro N., J. Revilla \& M. Neville. 1976. Carne de monte como una fuente de proteínas en Iquitos, con referencia especial en monos. Revista Forestal del Perú 6: 19-23.

Chiba S. 1999. Accelerated evolution of land snails Mandarina in the oceanic Bonin Islands. Evolution 53: 460-471.

Congrains C. 2010. Ayudando a descifrar el enigma taxonómico, el código de barras de ADN de Megalobulimus spp. (Mollusca, Gastropoda) del Departamento de San Martín - Perú. Título profesional. UNMSM, EAP. Genética y Biotecnología. Lima.

Dourojeanni M.J. 1965. Denominaciones vernaculares de insectos y algunos otros invertebrados en la Selva del Perú. Rev. per. Entom. 8 (1): 131-137.

Doyle J.J. \& J.L. Doyle. 1987. A rapid DNA isolation procedure for small amounts of fresh leaf tissue. Phytochemical Bulletin 19: 11-15. 
Emberton K.C. 1990. Acavid Land Snails of Madagascar: Subgeneric Revision Based on Published Data (Gastropoda: Pulmonata: Stylommatophora). Proceedings of the Academy of Natural Sciences of Philadelphia 142: 101-117.

Felsenstein J. 1985 Confidence limits on phylogenies: an approach using the bootstrap. Evolution 39: 783-791.

Feng Y., Q. Li, L. Kong \& X. Zheng. 2011. DNA barcoding and phylogenetic analysis of Pectinidae (Mollusca: Bivalvia) based on mitochondrial COI and 16S rRNA genes. Mol. Biol. Rep. 38 : 291-299.

Ferri G., M. Alù, B. Corradini, et al. 2009. Species Identification Through DNA “Barcodes”. Genetic Testing and Molecular Biomarkers 13 (3): 421-426.

Folmer O., M. Black, W. Hoeh, et al. 1994. DNA primers for amplification of mitochondrial cytochrome c oxidase subunit I from diverse metazoan invertebrates. Molecular Marine Biology and Biotechnology 3 (5): 294-299.

García-Villacorta R. 2009. Diversidad, composición y estructura de un hábitat altamente amenazado: los bosques estacionalmente secos de Tarapoto, Perú. Rev. peru. biol. 16 (1): 81-92.

Götting K-J. 1978. Lista preliminar de los caracoles terrestres de la región septentrional de Colombia. An. Inst. Inv. Mar.-Punta Betín (Santa Marta, Colombia) 10: 101-110.

Gram C.H., J.L. Parra, C. Rahbek \& J.A. McGuire. 2009. Phylogenetic structure in tropical hummingbird communities. PNAS 106 (2): 19673-19678.

Guindon S. \& Gascuel O. 2003. A simple, fast, and accurate algorithm to estimate large phylogenies by maximum likelihood. Systematic Biology 52 (5): 696-704.

Hajibabaei M., G.A. Singer, P.D. Hebert \& D.A. Hickey. 2007. DNA barcoding: how it complements taxonomy, molecular phylogenetics and population genetics. Trends Genet. 23 (4): 167-72.

Hall T. 1999. BioEdit: a user-friendly biological sequence alignment editor and analysis program for Windows 95/98/NT. Nucleic Acids Symp. Ser. 41: 95-98.

Handy S.M., J.R. Deeds, N.V. Ivanova, et al. 2011. A single-laboratory validated method for the generation of DNA barcodes for the identification of fish for regulatory compliance. J AOAC Int. 94 (1): 201-10.

Hausdorf B. 2006. The systematic position of Scolodonta Döring, 1875 and Scolodontidae H. B. Baker, 1925 (Gastropoda: Pulmonata). Zoologischer Anzeiger 245 (3-4): 161-165.

Hausdorf B. \& P. Bouchet. 2005. Working classification of the Gastropoda. Pulmonata, pp. 263-283. In: P. Bouchet and J.P. Rocroi, eds. Classification and nomenclator of gastropod families. Malacologia 47 (1/2): 1-397.

Hebert. P., A. Cywinska, S.L. Ball \& J.R. deWaard. 2003a. Biological identifications through DNA barcodes. Proc. R. Soc. Lond. B 270: 313-321.

Hebert P. \& T. Gregory. 2005. The promise of DNA barcoding for taxonomy. Syst. Biol. 54: 852-859.

Hebert P., S. Ratnasingham \& J.R. deWaard. 2003b. Barcoding animal life: cytochrome c oxidase subunit 1 divergences among closely related species. Proc. R. Soc. Lond. B (Suppl.) 270: S96-S99.

Herbert D.G. \& A. Mitchell. 2009. Phylogenetic relationships of the enigmatic land snail genus Prestonella: the missing African element in the Gondwanan superfamily Orthalicoidea (Mollusca: Stylommatophora). Biol. J. Linn. Soc. Lond. 96 (1): 203-221.

Hernández-Camacho J. 1992. Caracterización Geográfica De Colombia, In: G. Halffter, comp. La Diversidad Biológica de Iberoamérica I. Volumen Especial, Acta Zoológica Mexicana, nueva serie. Instituto de Ecología, A.C., Xalapa, México. Pp. 45-54.
Huang X. \& A. Madan. 1999. CAP3: A DNA Sequence Assembly Program. Genome Research., 9: 868-877.

Huelsenbeck J. \& F. Ronquist. 2001. MRBAYES: Bayesian inference of phylogenetic trees. Bioinformatics. 17 (8): 754-5

INIA. 2006. Proyecto Conservación in situ de cultivos nativos y sus parientes silvestres PER/98/G33. ANEXO 7 del Informe Anual 2005 y de Cierre. Sitios Objetivo del Proyecto: Costa Central, Selva Alta, Selva Baja, Sierra Centro, Sierra Centro Sur, Sierra Norte. Parte II - 3. Dirección de Investigación Agraria - DIA, Sub Dirección de Investigación de Recursos Genéticos y Biotecnología - SUBDIRGEB. http://www.inia.gob.pe/genetica/insitu/informes/Informe\%20Anual\%202005/GEF/LM-039/general.pdf

Lamas G. 1982. A preliminary zoogreographical division of Peru, based on buterfly distributions (Lepidoptera, Papilionidae). In: G.T. Prance, ed. Biological diversification in the Tropics. N.Y.: Columbia V. Press. Pp. 336-357.

Larkin M.A., G. Blackshields, N.P. Brown, et al. 2007. Clustal W and Clustal X version 2.0. Bioinformatics 23: 2947-2948.

Leme J.L.M. 1973. Anatomy and systematics of the Neotropical Strophocheiloidea (Gastropoda, Pulmonata) with the description of a new family. Arquivos de Zoologia, São Paulo 23 (5): 295-337.

Leme J.L.M. 1975. Ensaios filogenéticos em Pulmonata e sua importância na nova conceituação da superfamília Strophocheiloidea. Arq. Mus. Nac., RJ 55: 79-84.

Martens E.v. 1876. Die Bulimus-Arten aus der Gruppe Borus. Novit. Conchol. 1 (5): 1-26.

McCarthy C. 1996. Chromas: version 1.3. Griffith University, Brisbane, Australia.

Mello E. \& A. Coelho. 1989. Moluscos encontrados no sambaqui de Camboinhas, Itaipu, Niterói, estado do Rio de Janeiro, Brasil. Mem. Inst. Oswaldo Cruz, Rio de Janeiro 84 (4): 377-380.

Moritz C., J.L. Patton, C.J. Schneider \& T.B. Smith. 2000. Diversification of Rainforest Faunas: An Integrated Molecular Approach. Annu. Rev. Ecol. Syst. 31: 533-563.

Moura C.J., D.J. Harris, M.R. Cunha \& A.D. Rogers. 2008. DNA barcoding reveals cryptic diversity in marine hydroids (Cnidaria, Hydrozoa) from coastal and deep-sea environments. Zoological Scripta 37: 93-108.

Moussalli A., D.G. Herbert \& D. Stuart-Fox. 2009. A phylogeny of the cannibal snails of southern Africa, genus Natalina sensu lato (Pulmonata: Rhytididae): assessing concordance between morphology and molecular data. Mol. Phylogenet. Evol. 52 (1): 167-182.

Myers N. 1988. Threatened biotas: 'Hotspots' in tropical forests. The Environmentalist 8 (3): 187-208.

Myers N., R.A Mittermeier, C.G Mittermeier, et al. 2000. Biodiversity hotspots for conservation priorities. Nature 403: 853-858.

Nylander J.A.A. 2004. MrModeltest v2. Program distributed by the author. Evolutionary Biology Centre, Uppsala University.

Pacheco V., R. Cadenillas, E. Salas, et al. 2009. Diversidad y endemismo de los mamíferos del Perú. Rev. peru. biol. 16 (1): 5-32.

Parodiz J. 1982. Distribution and origin of the continental South America malacofauna. Malacologia 22 (1-2): 421-425.

Pilsbry H. 1893. Manual of Conch. (2) 8.

Pilsbry H. 1894-95. Manual of Conch. (2) 9.

Ponder W.F. \& D.R. Lindberg. 2008. Molluscan evolution and phylogeny: an introduction. In: Ponder and Lindberg, ed. Phylogeny and evolution of the Mollusca. Berkeley: University of California Press. Pp. 1-17.

Posada D. 2008. jModelTest: Phylogenetic Model Averaging. Molecular Biology and Evolution 25: 1253-1256. 
Primack R.B. \& E. Rodrigues. 2001. Biologia da Conservação. Londrina-Paraná, Brasil. 327 pp.

Ramírez R. 1993. A generic analysis of the family Systrophiidae (Mollusca: Gastropoda): Taxonomy, Phylogeny and Biogeography. Master of Arts (Systematics and Ecology). University of Kansas, Department of Systematics and Ecology (Lawrence, KS, USA). 218 pp.

Ramirez R. 1995. A new generic arrangement of the family Systrophiidae (Gastropoda, Stylommatophora) based on a phylogenetic hypothesis. XII Intern. Malacol. Congr., Vigo, España, Sept. 3-8 1995. (Resúmenes, p. 426-427).

Ramírez R. 2004. Sistemática e Filogeografia dos Moluscos do Ecossistema de "Lomas" do Deserto da Costa Central do Peru. Tese de Doutorado em Zoologia. PURS, Brasil.

Ramírez R. \& S. Cáceres. 1991. Caracoles terrestres (Mollusca, Gastropoda) comestibles en el Perú. Boletín de Lima (77): 67-74

Ramírez R., C. Paredes \& J. Arenas. 2003. Moluscos del Perú. Rev. Biol. Trop. 51 (suppl. 3): 225 - 284.

Ramírez R., J. Ramirez, \& P. Ramírez. 2011. The enigmatic phylogenetic position of Scolodontidae: A third Stylommatophoran clade. In: Monica Ammon Fernandez et al., comp. Tópicos em Malacologia: Ecos do XIX Encontro Brasileiro de Malacologia. Rio de Janeiro: Sociedade Brasileira de Malacología. Pp. 118-126.

Ramirez J., R. Ramírez, P. Romero, et al. 2009. Posición evolutiva de caracoles terrestres peruanos (Orthalicidae) entre los Stylommatophora (Mollusca: Gastropoda). Rev. peru. biol. 16 (1): 51-56.

Rengifo A., P. Padilla \& L. Mori. 2004. Caracterización morfológica del “congompe” Megalobulimus maximus (Sowerby 1825) y posibilidades de su cultivo, Iquitos - Perú. Manejo de Fauna Silvestre en Latinoamérica (Revista electrónica), Memorias VI Congreso Internacional sobre Manejo de Fauna Silvestre en la Amazonia y Latinoamérica, 5 - 10 Septiembre 2004, Iquitos - Perú, pp. 269-275.

Ríos M., M.J. Dourojeanni \& A. Tovar. 1973. La fauna y su aprovechamiento en Jenaro Herrera (Requena, Perú). Revista Forestal del Perú 5 (1-2): 1-23. http://cedinfor.lamolina. edu.pe/Articulos_RFP/

Rodríguez M. 2006. Arte rupestre en el departamento de San Martín. Tesis para optar el Título profesional de Licenciado en Arte. Univ. Nac. Mayor de San Marcos. Lima, Perú.

Romero P. 2010. Filogeografía de Systrophia helicycloides: El reflejo de la dinámica del bosque lluvioso tropical en los genes 16S rRNA y COI de moluscos terrestres. Tesis para optar Grado de Magíster, UPG. Fac. Ciencias Biológicas, Univ. Nac. Mayor de San Marcos. Lima, Perú.

Romero P. \& R. Ramírez. 2011. Divergencia intraespecífica y código de barras de ADN en Systrophia helicycloides (Gastropoda, Scolodontidae). Rev. peru. biol. 18 (2): 201-208.

Rowson B., P. Tattersfield \& W.O.C. Symondson. 2011. Phylogeny and biogeography of tropical carnivorous land-snails (Pulmonata: Streptaxoidea) with particular reference to East Africa and the Indian Ocean. Zool. Scr. 40 (1): 85-98.
Saitou N. \& M. Nei. 1987. The neighbour-joining method: a new method for reconstructing phylogenetic trees. Mol. Biol. Evol. 4: 406-425.

Salgado N. \& A. Coelho. 2003. Moluscos terrestres do Brasil (Gastrópodes operculados ou não, exclusive Veronicellidae, Milacidae e Limacidae). Rev. Biol. Trop. 51 (Suppl. 3): 149-189.

Shady R. 2000. Sustento socioeconómico de la sociedad de CaralSupe en los orígenes de la Civilización en el Perú. Arqueología y Sociedad 13: 49-66.

Simone L.R.L. 2006. Land and freshwater molluscs of Brazil. EGB, Fapesp, São Paulo. 390 pp.

Sigrist M.S. \& C.J. Carvalho. 2009. Historical relationships among areas of endemism in the tropical South America using Brooks Parsimony Analysis (BPA). Biota Neotropica, 9 (4): 79-90. Instituto Virtual da Biodiversidade, Brasil.

Stahl P.W. 2005. Selective faunal provisioning in the southern highlands of Formative Ecuador. Latin American Antiquity 16 (3): 313-328.

Swofford D. L. 2003. PAUP*. Phylogenetic Analysis Using Parsimony (*and Other Methods). Version 4. Sinauer Associates, Sunderland, Massachusetts.

Tamura K, J. Dudley, M. Nei \& S. Kumar. 2007. MEGA4: Molecular Evolutionary Genetics Analysis (MEGA) software version 4.0. Molecular Biology and Evolution 24: 1596-1599.

Tundisi J.G. \& T. Matsumura-Tundisi. 2008. Biodiversity in the Neotropics: ecological, economic and social values. Braz. J. Biol. 68(4, Suppl.): 913-915

Vaught K. 1989. A classification of the living Mollusca. Melbourne, Florida: American Malacologist, Inc.

Vences M., M. Thomas, A. van der Meijden, et al. 2005. Comparative performance of the 16S rRNA in DNA barcoding of amphibians. Front. Zool. 2: 5.

Vieira I., P. Toledo, J. Silva \& H. Higuchi. 2008. Deforestation and threats to the biodiversity of Amazonia. Braz. J. Biol. 68(4, Suppl.): 631-637.

Wade C. \& P. Mordan. 2000. Evolution within the gastropod mollusks; using the ribosomal RNA gene-cluster as an indicator of phylogenetic relationships. Journal of Molluscan Studies 66: 565-570.

Wade C., P. Mordan \& F. Naggs. 2006. Evolutionary relationships among the Pulmonate land snails and slugs (Pulmonata, Stylommatophora). Biological Journal of the Linnean Society 87 (4): 593-610.

Wang W., J. Yi, S. Ke \& M. Halmela. 2010. Gastropod Biological Fluid, Method of Making and Refining and Use. United States Patent Application Publication. Pub. N $^{\circ}$ US2010/0233111 A1. USPTO No: 19760WO01, Date of Filing: 06/24/2008.

Wong, E. H.-K. \& R.H. Hanner. 2008. DNA barcoding detects market substitution in North American seafood. Food Research International 41: 828-837.

Young B. 2007. Distribución de las especies endémicas en la vertiente oriental de los Andes en Perú y Bolivia. NatureServe, Arlington, Virginia, EE UU. 